\title{
Revisión de Heliotropium sects. Heliothamnus, Heliotrophytum, Hypsogenia, Plagiomeris y Platygine (Heliotropiaceae) en Chile
}

\section{Revision of Heliotropium sects. Heliothamnus, Heliotrophytum, Hypsogenia, Plagiomeris and Platygine (Heliotropiaceae) in Chile}

\section{Federico Luebert ${ }^{1,2}$}

${ }^{1}$ Universität Bonn, Nees-Institut für Biodiversität der Pflanzen, Meckenheimer Allee, D-53115 Bonn, Germany. fluebert@uni-bonn.de

${ }^{2}$ Departamento de Silvicultura y Conservación de la Naturaleza, Universidad de Chile, Santiago, Chile.

E-mail: fluebert@u.uchile.cl

\section{RESUMEN}

Se presenta una revisión taxonómica de las especies chilenas de Heliotropium (Heliotropiaceae), excluidas las de la sect. Cochranea que fue revisada en una contribución anterior. Ellas son Heliotropium amplexicaule (sect. Heliotrophytum), H. corymbosum (sect. Heliothamnus), H. curassavicum (sect. Platygyne), H. geissei (sect. Plagiomeris), H. microstachyum (sect. Hypsogenia), H. paronychioides (sect. Plagiomeris) y $\mathrm{H}$. patagonicum (sect. Platygyne). Se analiza en detalle la nomenclatura, iconografía, taxonomía, sistemática, distribución y bibliografía de cada una de las especies. Heliotropium corymbosum se reporta por primera vez para la flora de Chile y se efectúa la nueva combinación Heliotropium corymbosum var. grisellum, taxón que se ilustra por primera vez. Se discute la presencia de dos especies de Heliotropiaceae erróneamente mencionadas para Chile: Heliotropium angiospermum (sect. Schobera) y Euploca procumbens. Se concluye que la familia Heliotropiaceae está representada en Chile sólo por el género Heliotropium con 24 especies, incluyendo 17 previamente tratadas en la sect. Cochranea. Se ofrece una clave para la determinación de todas las especies chilenas de Heliotropium.

Palabras clave: Boraginaceae, Boraginales, flora, Heliotropioideae, taxonomía.

\section{ABSTRACT}

A taxonomic revision of the Chilean species of Heliotropium (Heliotropiaceae) is presented, excluding those of sect. Cochranea that were revised in a previous contribution. These species are Heliotropium amplexicaule (sect. Heliotrophytum), H. corymbosum (sect. Heliothamnus), H. curassavicum (sect. Platygyne), H. geissei (sect. Plagiomeris), H. microstachyum (sect. Hypsogenia), H. paronychioides (sect. Plagiomeris) and H. patagonicum (sect. Platygyne). I analyze in detail the nomenclature, iconography, taxonomy, systematics, distribution and bibliography of each species. Heliotropium corymbosum is newly reported for the flora of Chile and the new combination Heliotropium corymbosum var. grisellum is herewith proposed. This taxon is illustrated for the first time. I discuss the presence of two species of Heliotropiaceae erroneously reported for the Chilean flora: Heliotropium angiospermum (sect. Schobera) and Euploca procumbens. I conclude that the family Heliotropiaceae is represented in Chile only by the genus Heliotropium with 24 species, including 17 species previously treated under sect. Cochranea. I provide a key for the determination of all Chilean species of Heliotropium.

Keywords: Boraginaceae, Boraginales, flora, Heliotropioideae, taxonomy. 


\section{INTRODUCCIÓN}

La familia Heliotropiaceae (=Boraginaceae subfam. Heliotropioideae) está representada en Chile sólo por el género Heliotropium L. (Marticorena \& Quezada 1985; Zuloaga et al. 2008; Muñoz-Schick \& Morales 2013; Rodríguez et al. 2018). El último tratamiento taxonómico de Heliotropium para Chile data de hace casi un siglo (Johnston 1928a). Por lo tanto, no existe hasta ahora una revisión taxonómica actualizada de todas las especies presentes en Chile que reúna y sistematice la gran cantidad de información que se ha acumulado desde 1928 a la fecha y que permita la correcta identificación de las especies. En una contribución previa (Luebert 2013) se estudiaron las especies de Heliotropium de la sección Cochranea (Miers) Kuntze, que da cuenta de 17 de las 24 especies de Heliotropium conocidas para Chile. En este trabajo se presenta una revisión de las especies de Heliotropium que se encuentran en Chile y que no se incluyen en la sección Cochranea (tratada en Luebert 2013), siguiendo la clasificación infragenérica propuesta por Förther (1998) y modificada por Hilger \& Diane (2003). Aparte de la sección Cochranea, otras cinco secciones están presentes en Chile: H. sect. Heliothamnus I.M. Johnst., H. sect. Heliotrophytum G. Don, H. sect. Hypsogenia I.M. Johnst., H. sect. Plagiomeris I.M.Johnst y $H$. sect. Platygyne Benth.

De estas secciones, la primera cita para Chile proviene de Bertero (1829), quien describe $H$. chilense Bertero $(=H$. curassavicum L. sect. Platygyne). De Candolle (1845) describe Heliotropium paronychioides A.DC. (sect. Plagiomeris). Otras especies fueron posteriormente descritas por Philippi (1895), donde se incluye a H. geissei F.Phil. perteneciente a la sección Plagiomeris. Philippi (1881) segregó las especies de Heliotropiaceae en los géneros Cochranea Miers y Heliotropium, criterio seguido por Philippi (1895), pero estos fueron nuevamente reunidos en Heliotropium en las revisiones de Reiche (1907, 1910), Johnston (1928a) y Förther (1998), lo que se ha confirmado en estudios filogenéticos (Diane et al. 2002, Hilger \& Diane 2003, Luebert \& Wen 2008, Luebert et al. 2011) y plasmado en la revisión taxonómica de Heliotropiaceae (Diane et al. 2016). El trabajo de Johnston (1928a) es la revisión de Heliotropium en Sudamérica más completa que existe hasta hoy, en ella se incluyeron todas las especies conocidas para Chile a la fecha, se proveen claves y una clasificación infragenérica de las especies, aunque sin descripciones sistemáticas. Posteriormente Johnston (1937) discute la presencia en Chile de Euploca procumbens (Mill.) Diane \& Hilger (sub Heliotropium) y Heliotropium angiospermum Murray. Más tarde, Pisano (1976) reporta para el país a H. patagonicum (Speg.) I.M. Johnst. (sect. Platygyne); Arroyo \& Marticorena (1985), a H. microstachyum Ruiz \&
Pav. (sect. Hypsogenia) y finalmente, Ibáñez et al. (2011) a H. amplexicaule Vahl (sect. Heliotrophytum), todas descritas previamente para otros países.

La clasificación infragenérica de Johnston (1928a) fue revisada por Förther (1998), sin efectuar cambios sustanciales en lo que respecta a las especies chilenas del género. Los estudios filogenéticos realizados en los últimos años (Hilger \& Diane 2003; Luebert \& Wen 2008; Luebert et al. 2011; Luebert \& Muñoz-Schick 2014) confirman la monofilia de las secciones propuestas por Johnston (1928a) y Förther (1998) en las que se incluyen las especies chilenas.

Las especies que se tratan en este trabajo son Heliotropium amplexicaule (sect. Heliotrophytum), H. corymbosum Ruiz \& Pav. (sect. Heliothamnus), H. curassavicum (sect. Platygyne), H. geissei (sect. Plagiomeris), H. microstachyum (sect. Hypsogenia), H. paronychioides (sect. Plagiomeris) y H. patagonicum (sect. Platygyne). Se analiza en detalle la nomenclatura, iconografía, taxonomía, sistemática, distribución y bibliografía de cada una de estas especies. Se discute la presencia en Chile de Heliotropium angiospermum (sect. Schobera (Scop.) I.M. Johnst.) y Euploca procumbens (三Heliotropium procumbens Mill.), erróneamente mencionadas para Chile por Johnston (1928a) y Marticorena \& Quezada (1985). Finalmente, se proveen un catálogo y una clave para la determinación de todas las especies de Heliotropium presentes en Chile.

La sinonimia que se incluye corresponde a los nombres más utilizados en la literatura, pero no pretende ser exhaustiva. Para antecedentes más detallados sobre la sinonimia de las especies véase Johnston (1928a, 1964), Gangui (1955), Förther (1998), Zuloaga et al. (2008) y di Fulvio \& Ariza Espinar (2016). Las dimensiones corresponden a mediciones efectuadas en los ejemplares de herbario, así como a datos obtenidos de las descripciones originales de las especies y de sus sinónimos. Se revisó material en los siguientes herbarios: A, AAU, B, BM, BONN, C, CONC, E, EIF, F, FI, G, GH, GOET, H, HAL, K, L, M, MSB, MA, NY, P, QCA, S, SGO, U, ULS, US, W, WU. Para la confección de los mapas se utilizó la información de localidades georreferenciadas de los especímenes examinados. Cuando las coordenadas no estaban indicadas, las localidades fueron georreferenciadas utilizando Risopatrón (1924) y el sitio http://www.geonames. org/. Los mapas fueron confeccionados en R v.3.6.3 (R Core Team 2017) utilizando los paquetes maps v.3.3.0 y mapdata v.2.3.0 (Becker et al. 2016, 2017).

\section{TAXONOMÍA}

Heliotropium amplexicaule Vahl, Symb. Bot. 3:21, 1794. TIPO: Montevideo, P. Commerson s.n. (holotipo, C[C10008720]!; 
isotipos, MPU[MPU022410], P[P00482088]!, P-JU-6566!; posible isotipo G-DC[G00147911]!).

Heliotropium anchusaefolium Poir., Encycl. [J. Lamarck \& al.] Suppl. 3: 23. 1813. TIPO: "Buenos Ayres", P. Commerson s.n. (holotipo, P-JU-6566!; isotipos, C[C10008720]!, FIW[FI006545]!, MPU[MPU022410], P[P00482088]!; posible isotipo G-DC[G00147911]!).

Heliotropium bolivianum Rusby, Mem. Torrey Bot. Club 4: 225. 1895. TIPO: Vic. Cochabamba, 1891, M. Bang 926 (holotipo, NY[NY00335389]! [foto MSB!]; isotipos BM[BM000992035]!, E[E00394549]!, F[F0052472F]!, G[G00081516]!, GH[GH00097602]!, LE no visto, MO694704 [foto!], MSB[MSB002990]!, NY[NY00335390]!, US[US00110843]! [foto MSB!], W-9029!, WIS [WISv0255176]).

Heliotropium lithospermifolium (DC.) Speg., Contr. Fl. Sierra Vent.: 44. 1896; Heliophytum lithospermifolium DC., Prodr. (DC.) 4: 554. 1845. TIPO: Brasilia meridionalis, F. Sellow s.n. (holotipo, G-DC[G00147835]!; isotipos BREM no visto, LE no visto, P[P00482091]! [foto MSB!]; posibles isotipos HAL[HAL0071595]!, TUB no visto, W!).

Tournefortia sessilifolia Poir., Encycl. [J. Lamarck \& al.] 5: 360. 1804. TIPO: Buenos Ayres, P. Commerson s.n. (holotipo, P-LA[P00357296]!).

Para una sinonimia más completa véase Johnston (1928a, 1964), Gangui (1955), Förther (1998), Zuloaga et al. (2008), di Fulvio \& Ariza Espinar (2016).

Iconografía: Gangui (1955: 529, fig. 9), Dawson (1965: 108, fig. 38), Smith (1970: 43, est. 8j-I), Guimarães et al. (1971: Est. XXIV), Pérez-Moreau (1979: 220, fig. 100; 1994: 19, fig. 7ae), Pérez-Moreau \& Cabrera (1983: 266, fig. 107A-E), Autrey et al. (2005: 23, fig. 6), Melo \& Semir (2008: 758, figs. 1-6), Pérez-Moreau et al. (2017: 54, fig. 27).

Referencias: Johnston (1928a: 21; 1964: 140), Gangui (1955: 526), Dawson (1965: 108), Munz \& Keck (1965: 554), Correll \& Johnston (1970: 1287), Smith (1970: 44), Pérez-Moreau (1979: 219; 1994: 18), Pérez-Moreau \& Cabrera (1983: 262), Liogier (1995: 321), Craven (1996: 546), Melo \& Semir (2008: 756), Ibáñez et al. (2011), di Fulvio \& Ariza Espinar (2016: 752), Luebert (2017: 792), Pérez-Moreau et al. (2017: 54).

Hierba con base leñosa o subarbusto decumbente, densamente ramificado, $0,2-0,6 \mathrm{~m}$ de alto con la ramillas glanduloso-pubescentes. Hojas alternas, solitarias, sésiles, pubescentes con abundantes pelos glandulosos en ambas caras; lámina elíptica, oblonga u oblanceolada, concolora, con nervios bien marcados en las dos caras, 1,5-9 x 0,3$1,8(-2,5) \mathrm{cm}$, margen ondulado o lobulado, base atenuada, ápice agudo o redondeado. Inflorescencias terminales dicotómicamente ramificadas en hasta 3 niveles, de hasta $10 \mathrm{~cm}$ de largo, con los ejes vellosos. Flores sésiles, 4-8 mm de largo. Cáliz persistente, dividido hasta la base; sépalos lineales a lanceolados, glanduloso-pubescentes en ambas caras, 2-3,5(-5) mm de largo, 1-2 $\mathrm{mm}$ de ancho en la base, base no acrescente, ápice agudo, no acuminado. Corola infundibuliforme, violeta o azul, raramente blanca, 4-8 mm de largo, 4-8 mm de diámetro; lóbulos redondeados, 1-1,5 $\mathrm{mm}$; tubo pubescente por fuera, velloso por dentro por sobre la mitad de su longitud. Estambres inclusos; filamentos adnados a los pétalos; anteras no coherentes, lineares o angostamente ovadas, 1-1,5 mm, margen no papiloso; base redondeada, atenuada, localizada aproximadamente sobre el ápice de la columna estigmática; ápice apiculado, no papiloso. Ovario glabro, 0,5-0,7 mm de alto, ca. 0,5 mm de diámetro, con disco nectarífero en la base. Columna estigmática cónica, sésil, ca. 0,3-0,4 mm de largo, ca. 0,5-0,7 mm de ancho en la base, pubescente. Frutos secos, glabros, 1,5-2,5 x $3 \mathrm{~mm}$, separándose en 2 nueces biseminadas. Nueces con una cavidad vacía adicional, superficie dorsal rugosa y algo tuberculada.

Distribución. Centro y norte de Argentina, sur de Bolivia, sur de Brasil y Uruguay. Maleza introducida en todos los continentes. En Chile ha sido recientemente reportada como especie alóctona (Ibáñez et al. 2011).

Especímenes examinados (selección): ARGENTINA, Prov. Buenos Aires, Pigue, 13-XII-1938, W.J. Eyerdam, A.A. Beetle \& E. Grondona 23401 (G); Prov. Córdoba, Deán Funes, 2-XI1945, A.R. Cuezzo 730 (BM); Prov. Corrientes, ruta 23, 20 km E de Mercedes, 29-X-1973, A. Schinini 7571 (G); Prov. Entre Ríos, Salto Grande, Río Uruguay, Casa de Piedra, 15 m, 30-X-1978, S.A. Renvoize 2868 (B); Prov. Salta, Alrededores del pueblo de Amblayo, 2.300-2.600 m, 1-IV-1990, L. Novara \& R. Neuman 715 (G); Prov. San Juan, Estancia Maradona, 1.000-1.500 m, 7-II-1986, R. Kiesling, N. Bacigalupo, E. Gómez Sosa 5975 (P); Prov. Tucumán, Tafí del Valle, al pie del cerro Pelado, 2.200 m, 24-I-1950, H. Sleumer 129 (B).

BOLIVIA. Depto Chuquisaca, La Compuerta, carretera de Sucre a Chiqui Chiqui, $18^{\circ} 50.5^{\prime} \mathrm{S}, 65^{\circ} 7.8^{\prime} \mathrm{W}, 2.356 \mathrm{~m}, 5$-VIII2007, M. Velayos, C. Aedo \& C. Monge 11180 (MA).

BRASIL, Minas Gerais, Biribiry, 14-III-1892, A. Glaziou 19679 (P); Rio Grande do Sul, 1833, Gaudichaud 638, 639 (P), 1816- 
1821, A. Saint-Hilaire 2584 (P).

CHILE, Región Metropolitana, Prov. Santiago, Campus San

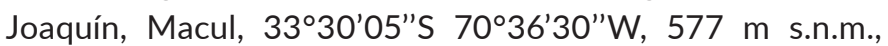
6-IV-2010, S. Ibáñez 01 (SGO).

URUGUAY, Depto. Montevideo, Atahualpa, XI-1925, W.G.F Herter 79759 (F).

Comentarios. Heliotropium amplexicaule pertenece a la sección Heliotrophytum, un grupo monofilético formado por cuatro especies nativas de Sudamérica oriental subtropical (Johnston 1928a, Förther 1998, Luebert et al. 2011). No hay otras especies de esta sección en Chile.

Esta especie, ampliamente distribuida en las zonas subtropicales de Sudamérica oriental, ha sido sólo recientemente registrada para Chile sobre la base de una colección (Ibáñez et al. 2011). Su condición de maleza ha sido reportada para diferentes partes del mundo, pero aún debe ser confirmada en Chile mediante futuras recolecciones.

Los materiales tipo de $\mathrm{H}$. anchusaefolium conservados en P-JU y P provienen de Montevideo, y no de Buenos Aires como consta en el protólogo. No hay materiales atribuibles a $H$. anchusaefolium provenientes de Buenos Aires en P-JU. Por esta razón considero que estos materiales son también isotipos de $\mathrm{H}$. amplexicaule, lo que significa que $\mathrm{H}$. anchusaefolium y $\mathrm{H}$. amplexicaule son sinónimos homotípicos. El material de FI-W dice provenir de Buenos Aires, pero no hay indicación de quién es el recolector.

El material tipo de Tournefortia sessilifolia, recolectado por Commerson en Buenos Aires, pertenece también a esta especie. Según Förther (1998), este material se encuentra en P-JU y podría ser homotípico con $\mathrm{H}$. anchusaefolium, lo que, por lo dicho, parece no ser efectivo. El tipo de Tournefortia sessilifolia está en P-LA.

Heliotropium corymbosum var. grisellum (I.M. Johnst.) Luebert, comb. nov. Basiónimo: Heliotropium arborescens var. grisellum I.M. Johnst., Contr. Gray Herb. 81: 40. 1928. TIPO: Perú. Depto. Moquegua, Carumas, 2700 m, II-III.1925, A. Weberbauer 7272 (holotipo, F[F0063163F]! [foto BM!, K!, MSB!]; isotipos G[G00169836]!, GH[GH00097598]!, K[K000438850]!, S[S06-4218]!). Fig. 1.

Referencias: Johnston (1928a: 40), Macbride (1960: 558).
Arbusto erecto, densamente ramificado, 1-2,5 m de alto con las ramillas juveniles pubescentes. Hojas alternas, solitarias, sésiles o cortamente pecioladas, pubescente, estrigosa en la superficie adaxial, lanoso-tomentosa en la superficie abaxial; peciolo ca. 1-2 mm de largo; lámina elíptica, discolora, con nervios bien marcados en las dos caras (especialmente los secundarios), 4-8 (-20) x 1-4,5(-15) cm, margen entero, base atenuada, ápice usualmente agudo o raramente redondeado o emarginado. Inflorescencias terminales dicotómicamente ramificadas en hasta cuatro niveles, de hasta $9 \mathrm{~cm}$ de largo, con los ejes vellosos. Flores sésiles, 9-13 mm de largo. Cáliz persistente, dividido hasta la base; sépalos lineales a lanceolados, estrigoso-vellosos por fuera, glabros por dentro, 4-6 mm de largo, 0,5-1 $\mathrm{mm}$ de ancho en la base, base usualmente acrescente en la madurez y entonces de hasta $2 \mathrm{~mm}$ de ancho, ápice agudo, acuminado. Corola infundibuliforme, blanca con el centro amarillento, tornándose azul, malva o violeta en la madurez, 9-13 mm de largo, 4-7 mm de diámetro; lóbulos redondeados, 1,52,5 x 1-2 mm; tubo velloso por fuera, glabro por dentro. Estambres inclusos; filamentos con la porción proximal adnada a los pétalos, y la distal libre de ca. 0,1-0,2 mm de largo; anteras coherentes, lineares, 1-1,5 mm, margen cortamente papiloso; base redondeada, cordada, localizada aproximadamente sobre la porción receptiva de la columna estigmática aproximadamente en la mitad del tubo; ápice curvo, papiloso. Ovario glabro, 0,3-0,4 mm de alto, ca. 0,5 $\mathrm{mm}$ de diámetro, con disco nectarífero desarrollado en la base. Estilo más largo que la columna estigmática, 1-2 mm. Columna estigmática cónica, 0,4-0,8 mm de largo, ca. 0,5$0,6 \mathrm{~mm}$ de ancho en la base, finamente papiloso en los ribetes. Frutos secos, glabros, café oscuros, ca. 0,5 x 0,8 $\mathrm{mm}$ separándose en 4 nueces uniseminadas. Nueces sin cavidades vacías, superficie dorsal tuberculada.

Distribución: Sudoeste de Perú (Departamentos de Arequipa y Moquegua) y norte de Chile (Región de Arica y Parinacota) (Fig. 2), en los faldeos precordilleranos de la vertiente occidental de la cordillera de los Andes y en formaciones de lomas, entre 200 y 3300 m, generalmente en laderas áridas con cactáceas columnares (e.g., Haageocereus Backeb.) sobre sustratos rocosos, pedregosos o arenosos, en terrazas de cultivo abandonadas y en los márgenes de terrenos de cultivos. 


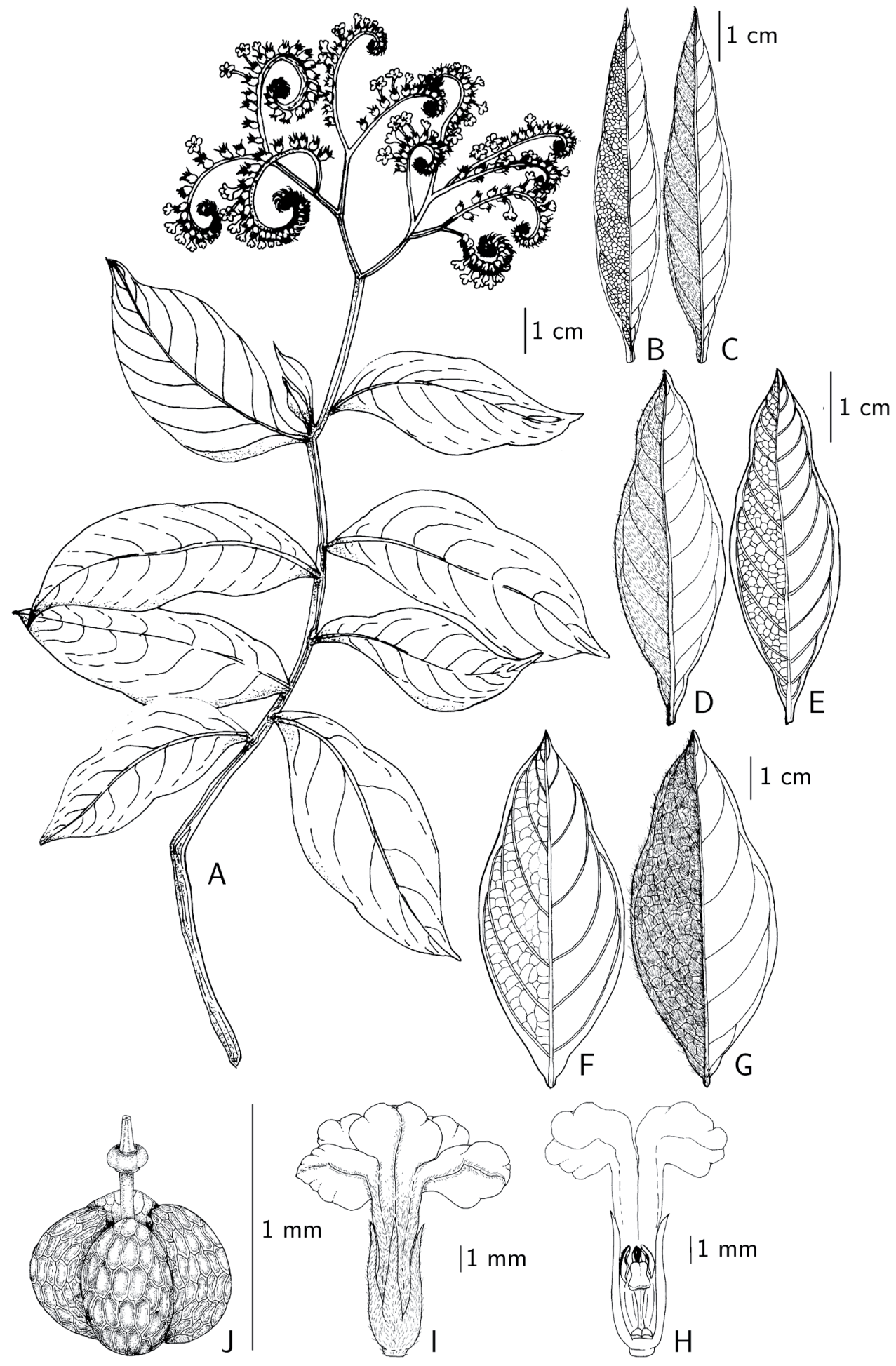

Figura 1. Heliotropium corymbosum var. grisellum. A, Hábito; B-G, Hojas, variabilidad de tamaño y forma, B,E,F, superficie adaxial, C,D,F, superficie abaxial; H, Flor, vista interior; I, Flor, vista exterior; J, Fruto con estilo y columna estigmática. A, F-G de Weberbauer 7272 (F); B-C, H-I de Weigend \& Baldárrago 9364 (B); D-E de Weigend \& Förther 97/845 (B); I de Weigend \& Ackermann 9292 (B). Dibujo de Galina Karabascheva, 2012. / Heliotropium corymbosum var. grisellum. A, Habit; B-G, Leaves, size and shape variation, B,E,F, adaxial surface, C,D,F, abaxial surface; H, Flower, inner view; I, Flower, outer view; J. Fruit with style and stigmantic head. A, F-G from Weberbauer 7272, F; B-C, H-I from Weigend \& Baldárrago 9364, BSB; D-E from Weigend \& Förther 97/845, BSB; I from Weigend \& Ackermann 9292, BSB. Drawn by Galina Karabascheva, 2012. 


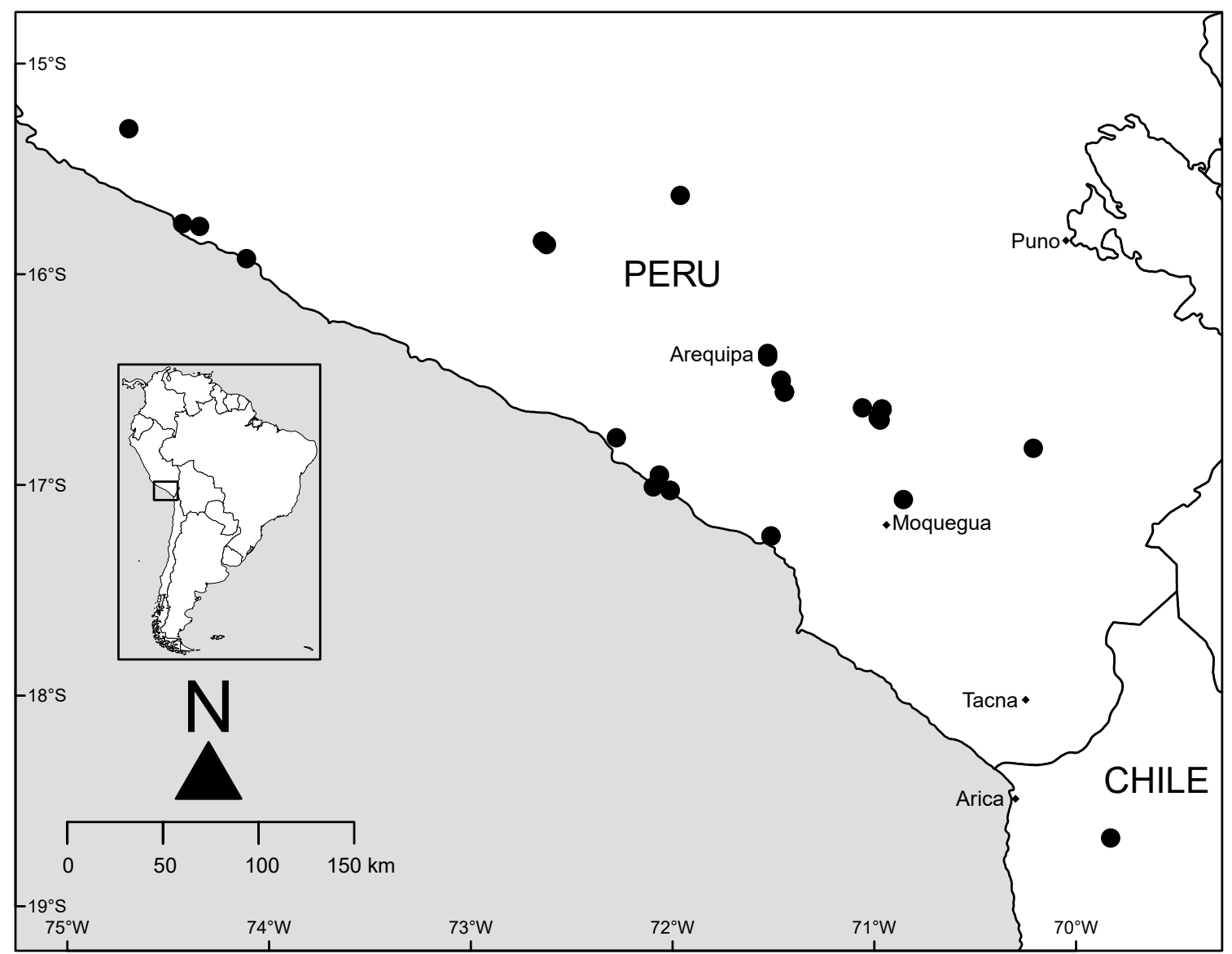

FiguRA 2. Mapa de distribución de Heliotropium corymbosum var. grisellum. / Distribution map of Heliotropium corymbosum var. grisellum.

Especímenes examinados: PERÚ, Depto. Arequipa, Prov. Caravelí, Magdalena, J. v. Warscewicz s.n. (K); Atiquipa, A $2 \mathrm{~km}$ este del cementerio de la comunidad de Atiquipa, $15^{\circ} 45^{\prime} 49^{\prime \prime}$ S, 74²0'56"W, 496 m, 15-XI-2005, M.O. Dillon, J. Wen, V. Quipuscoa, E. Ortiz, M. Corrales \& G. Castillo 8838 (F); ca. $24 \mathrm{~km} \mathrm{~N}$ of puerto Chala, $750 \mathrm{~m}, 8$-VII-1956, M. Køie s.n. (C); Mellem Chala og Yanca, 200 m, 18-III-1953, E. Petersen \& J.P. Hjerting 1136 (C); N puerto Chala, 400 m, 18VIII-1957, H. Ellenberg 2666 \& 2690 (U); Prov. Condesuyos, road from Aplao (Castillo) to Chuquibamba, Iraquy, $5.5 \mathrm{~km}$

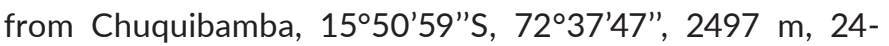
VII-2010, M. Weigend, F. Cáceres \& U. Baldárrago 9384 (BONN); Chuquibamba, 3200 m, 1-I-1938, D. Stafford 1200 (BM, K); Chuquibamba, 2700 m, 17-III-1967, H. Ellenberg 152 (U), Prov. Camaná, $14 \mathrm{~km}$ on road south of Chala, 400-500 m, 21-IX-1938, C.R. Worth \& J.L. Morrison 15686 (K); Prov. Caylloma, Cabanaconde, 3300 m, 28-II-1980, R. Lilljekvist 91 (C); Prov. Arequipa, foot of El Misti, 2438 m, 10-IV-1937, T.G. Tutin 918 (BM); near Arequipa, 2-X -2002, M. Ackermann, R. Aguilar, H. Echeñique \& L. Machaca 422 (B); La Hacienda, Mollebaya, 2460 m, 21-II-2002, F. Cáceres, J. Zúñiga \& L.
Martínez 3050 (B); Mollebaya, La Hacienda 16²9'38'S, 71²7' 59'W, 2507 m, 18-IV-2006, M. Weigend, F. Cáceres \& C. Schwarzer 8288 (BONN); Quequeña, 11-VII-1863, J. Isern 145 [ISERMA 2512] (MA); Quequeña, $40 \mathrm{~km}$ south of Arequipa, 17-IX-1938, W.J. Eyerdam \& A.A. Beetle 22180 (K); Prov. Islay, lomas of Mollendo, ca. $8 \mathrm{~km} \mathrm{NW}$ of Islay, $510 \mathrm{~m}$, 20-XI-1983, M.O. Dillon \& D. Dillon 3943 (F); quebrada Yura (=Llura) above Matarani, 400-800 m, 14-X-1997, M. Weigend $\&$ H. Förther $97 / 879$ (BONN); lomas de Lluta [sic], road from Arequipa to the coast, 350 m, 18-X-2002, M. Ackermann \& F. Cáceres 432 (B, K, MA); lomas de Lluta [sic], road from Arequipa to the coast, $350 \mathrm{~m}, 18-\mathrm{X}-2002$, M. Ackermann \& F. Cáceres 433 (B); Mollendo, lomas y quebradas, $600 \mathrm{~m}$, 8-XI-2002, Cáceres et al. 2874 (B); Mollendo, quebrada del Guerrero, laderas y quebradas, lomas, 600 m, VIII-2003, Cáceres et al. 3263 (B); baños de Jesús [Yura?], $2895 \mathrm{~m}$, 9-II1943, C. Sandeman 3821 (K); lomas de Jesús, 800-950 m, 25-III-1998, FLSP 2145 (P); Depto. Moquegua, Prov. General Sánchez Cerro, road from Arequipa to Omate, above Omate, $16^{\circ} 37^{\prime} 29^{\prime \prime} \mathrm{S}, 71^{\circ} 3^{\prime} 48^{\prime \prime} \mathrm{W}, 2800$ m, 7-XII-2006, M. Ackermann \& F. Cáceres 657 (B, MSB); Omate, Carbaya, end of road going 
up the Omate valley, 16 $37^{\prime} 51^{\prime \prime} \mathrm{S}, 70^{\circ} 57^{\prime} 59^{\prime \prime} \mathrm{W}, 2799 \mathrm{~m}, 21$ VII-2010, M. Weigend \& U. Bladárrago 9362-9364 (BONN); Omate, orchards of Omate, 16 $40^{\circ} 23^{\prime \prime} \mathrm{S}, 7^{\circ} 59^{\prime} 7^{\prime \prime} \mathrm{W}, 2103$ m, 29-III-2009, M. Weigend \& M. Ackermann 9292 (BONN); Laje, 2180 m, 8-IV-2002, F. Cáceres, R. Aguilar \& M. Hinojosa 3017 (B); Prov. Mariscal Nieto, supra Torata, 17³'37'S, 7051'38", 2600m, 12-IV-2005, C. Aedo \& A. Galán de Mera 11325 (MA); $12 \mathrm{~km}$ E Moquegua on road to Torata 1750m, 14-X-1997, M. Weigend \& H. Förther 97/845 (BONN); Depto, Prov. y localidad indefinidos, 1839-1840, C. Gay s.n. (P); H. Cuming 946 (K).

CHILE, Región de Arica y Parinacota, Prov. Arica, Nordchile, Agua de Quero, am Westfuss der Cordillera de los Andes,

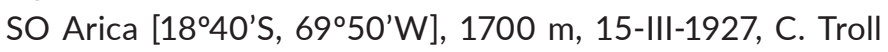
3246 (B, M).

Comentarios: Heliotropium corymbosum pertenece a la sección Heliothamnus, cuyo centro de diversidad se encuentra en los Andes de Perú y Ecuador, con una especie, H. rufipilum (Benth.) I.M. Johnst., que alcanza a Centroamérica (Johnston 1928a, Gibson 1970, Frohlich 1981, Miller 2001, 2012). Esta sección es un grupo monofilético hermano de todas las restantes secciones del género Heliotropium, pero las relaciones filogenéticas dentro de la sección permanecen todavía sin resolver (Luebert et al. 2011).

Esta especie es citada aquí por primera vez para Chile sobre la base de un material recolectado por Carl Troll y redescubierto en los herbarios de Berlin-Dahlem (B) y Munich (M). Este material pasó inadvertido a los botánicos desde 1927. No es sorprendente que esta especie se encuentre presente en el norte de Chile, ya que varios taxones muestran continuidad en su distribución geográfica entre la precordillera del sur de Perú y norte de Chile (Pinto \& Luebert 2009, Schwarzer et al. 2010, Ruhm et al. 2020). La localidad indicada por Troll es muy precisa, aunque al parecer de muy difícil acceso en el presente. Troll la habría alcanzado cabalgando desde Tignamar, y desde donde posteriormente se desplazó hacia el pueblo de Timar (Troll \& Monheim 1985). La presencia de una "Boraginee con flores violeta" en este lugar está consignada en su diario de campo (conservado en los archivos del Instituto de Geografía, Universidad de Bonn). La localidad se ubica en la parte superior del Desierto tropical interior con vegetación escasa (Luebert \& Pliscoff 2017).

Esta especie es tratada por Johnston (1928a), Macbride (1960) y Brako \& Zarucchi (1993) bajo el nombre Heliotropium arborescens L. Luebert et al. (2010) mostraron que dicho nombre fue erróneamente aplicado por estos autores y que el nombre más antiguo disponible para esta especie es Heliotropium corymbosum. La variedad grisellum, descrita por
Johnston (1928a) bajo Heliotropium arborescens, requiere por lo tanto ser combinada bajo Heliotropium corymbosum, que es lo que aquí se ha efectuado. Brako \& Zarucchi (1993) consideran esta variedad como un sinónimo de la especie (sub. H. arborescens). Sin embargo, esta difiere de la variedad típica por las hojas más grandes, con indumento más largo y canescente y con los nervios secundarios de las hojas más marcados, además de un rango geográfico más austral, donde tiende a ser más similar a $\mathrm{H}$. incanum Ruiz \& Pav. o H. mandonii I.M.Johnst (cf. Johnston 1928a, Macbride 1960).

Según anotación de Weberbauer, la especie es localmente conocida en Perú como "Cayareja".

Heliotropium curassavicum L., Sp. PI. 1:130. 1753. TIPO: Heliotropium curassavicum, foliis lini umbilicati, in Morrison, PI. Hist. 3: 452, sect. 11, t. 31, f. 12.1699 (lectotipo, designado por Verdcourt 1991: 67; tipótipo OXF [Herb. Morrison] [foto!], fide Förther 1998, Jarvis 2007).

Heliotropium chilense Bertero, nomennudum, Mercurio Chileno 14: 647. 1829. TIPO: Chili, in arenosis prope lacum Aculeo, III1818, C. Bertero [320] (lectotipo, P[P00610168]!, designado por Förther (1998: 185); isolectotipos, G-DC[G00147591]!, GH[GH00097606] fototipo!, P[P00610167!, P00610169!], SGO 54408!).

Para una sinonimia detallada véase Johnston (1928a, 1964), Gangui (1955), Förther (1998).

Iconografía: Liogier (1957: 276, fig 120A), Dawson (1965: 110, fig. 39D), Marticorena (1968: 41, fig. 14A [polen]), Nowicke (1969: 38), Navas (1979: 351, lam. 10E-I), Miller (1988: 501), Martins (1990: 12, tab. 26/12), Verdcourt (1991: 66, fig. 18/2), Pérez-Moreau (1994: 14, fig. 4a-c), Correa (1999: 135, fig. 92), Melo \& Semir (2008: 763, fig.12-16), Juan \& Talavera (2011: 531, lam. 124).

Referencias: Reiche (1907: 120; 1910: 194), Johnston (1928a: 14; 1935: 57; 1936: 330; 1949: 315; 1964: 145), Ewan (1942: 54), Gangui (1955: 510), Liogier (1957: 276; 1994: 163; 1995: 322), Dawson (1965: 109), Correll \& Johnston (1970: 1288), Gibson (1970: 141), Navas (1979: 53), Correll \& Correll (1982: 1203), Howard (1989: 202), Rodríguez (1993: 86), PérezMoreau (1994: 13); Correa (1999: 132), Craven (1996: 634), Miller (2001: 448), Melo \& Semir (2008: 759), di Fulvio \& Ariza Espinar (2016: 759), Luebert (2017: 793).

Hierba perenne, postrada o ascendente, $10-50(-70) \mathrm{cm}$ de alto, glabra, suculenta. Hojas alternas o subopuestas, solitarias, sésiles, glabras; lámina espatulada, lineal-espatulada o 
lineal lanceolada, glauca, concolora, con los nervios poco marcados, 1,5-8 $\times$ 0,2-1,5 cm, margen entero, base atenuada, ápice usualmente obtuso o redondeado. Inflorescencias terminales o axilares, simples o dicotómicamente ramificadas en hasta dos niveles, de hasta $5 \mathrm{~cm}$ de largo. Flores sésiles, 2-3 mm de largo. Cáliz persistente, dividido hasta la base; sépalos lineales a aovado-lanceolados, glabros, 0,5-1,5 mm de largo, 0,2-1 mm de ancho en la base, ápice agudo. Corola hipocrateriforme, blanca con centro amarillento, centro tornándose azul o violeta en la madurez, 2-3 mm de largo, 1,52,5 mm de diámetro; lóbulos obtusos, ca. 0,7-1 × 0,5-0,7 mm; tubo glabro en ambas caras. Estambres inclusos; filamentos con la porción proximal adnada a los pétalos, y la distal libre de ca. 0,1 mm de largo; anteras libres, aovadas, ca. 0,4-0,8 $\mathrm{mm}$, base redondeada, cordada, localizada aproximadamente sobre la porción receptiva de la columna estigmática cerca de la mitad del tubo; ápice obtuso a acuminado, no papiloso. Ovario glabro, ca. 0,5 mm de alto, ca. 0,7 mm de diámetro, con disco nectarífero desarrollado en la base. Estilo inconspicuo. Columna estigmática cónica, 0,4-0,5 mm de largo, ca. 0,3-0,5 $\mathrm{mm}$ de ancho en la base, ápice lobado, glabra. Frutos secos, glabros, café claro, ca. 1,2-2,5 x 1,2-2,5 mm, separándose en 4 nueces uniseminadas. Nueces sin cavidades vacías, superficie dorsal lisa o ligeramente reticulada.

Distribución: Especie ampliamente distribuida en las zonas tropicales y subtropicales de América, en zonas litorales o en terrenos salinos interiores. En Chile se encuentra desde el extremo norte hasta la Región de O'Higgins (Fig. 3), en áreas salobres entre el nivel del mar y 2000 (4400) m. Introducida en todos los otros continentes.

Especímenes examinados (sólo Chile): CHILE, Región de Arica y Parinacota, Prov. Parinacota, vega de Parinacota, 18`13'S, 69¹4'W, 4400 m, 19-V-1979, C. Villagrán, M.T.K. Arroyo, J. Armesto \& P. Uslar 1315 (CONC); Prov. Arica, valle de Lluta, Boca Negra, $18^{\circ} 24^{\prime}$ S, 6958'W, 860 m, 21-III-1987, O. Matthei \& R. Rodríguez 339 (CONC); quebrada de Lluta, $18^{\circ} 24^{\prime} \mathrm{S}, 70^{\circ} 10^{\prime} \mathrm{W}, 305 \mathrm{~m}, 21-\mathrm{IX}-2005$, F. Luebert \& N. García 2521 (SGO); qda. de Lluta, Chacalluta, 13-IX-1955, M. Ricardi 3320 (CONC); quebrada de Lluta, $18^{\circ} 24^{\prime} \mathrm{S}, 70^{\circ} 18^{\prime} \mathrm{W}, 40 \mathrm{~m}$, 18-VII-1991, G. Arancio 91069 (ULS); quebrada Lluta, Rosario, 380 m, 10-II-1948, F. Sudzuki 209 (SGO); valle de Lluta, 14-IX-1959, G. Montero 6183 (CONC); valle de Lluta, 18-I-1950, A. Pfister s.n. (CONC 9492); quebrada de Lluta, 11-VII-1967, G. Espinoza s.n. (CONC 32978); Poconchile, 570 m, 2-I-1974, J. Castillo 193 (CONC); Poconchile, 500 m, 8-V1972, M. Ricardi, E. Weldt \& M. Quezada 307 (CONC); río San José, quebrada junto a la playa, $18^{\circ} 28^{\prime} \mathrm{S}, 70^{\circ} 19^{\prime} \mathrm{W}, 10 \mathrm{~m}$, 14-V-1979, C. Villagrán, M.T.K. Arroyo, J. Armesto \& P. Uslar
1002 (CONC); Arica, in arenosis, V-1854, W. Lechler 1553 (HAL, S, W); Arica, 1-X-1931, F. Jaffuel 1671 (CONC, GH); Arica, X-1914, O. Buchtien 4377 (US); Arica, X-1914, O. Buchtien 4378 (US); Arica, X-1914, O. Buchtien 4379 (US);

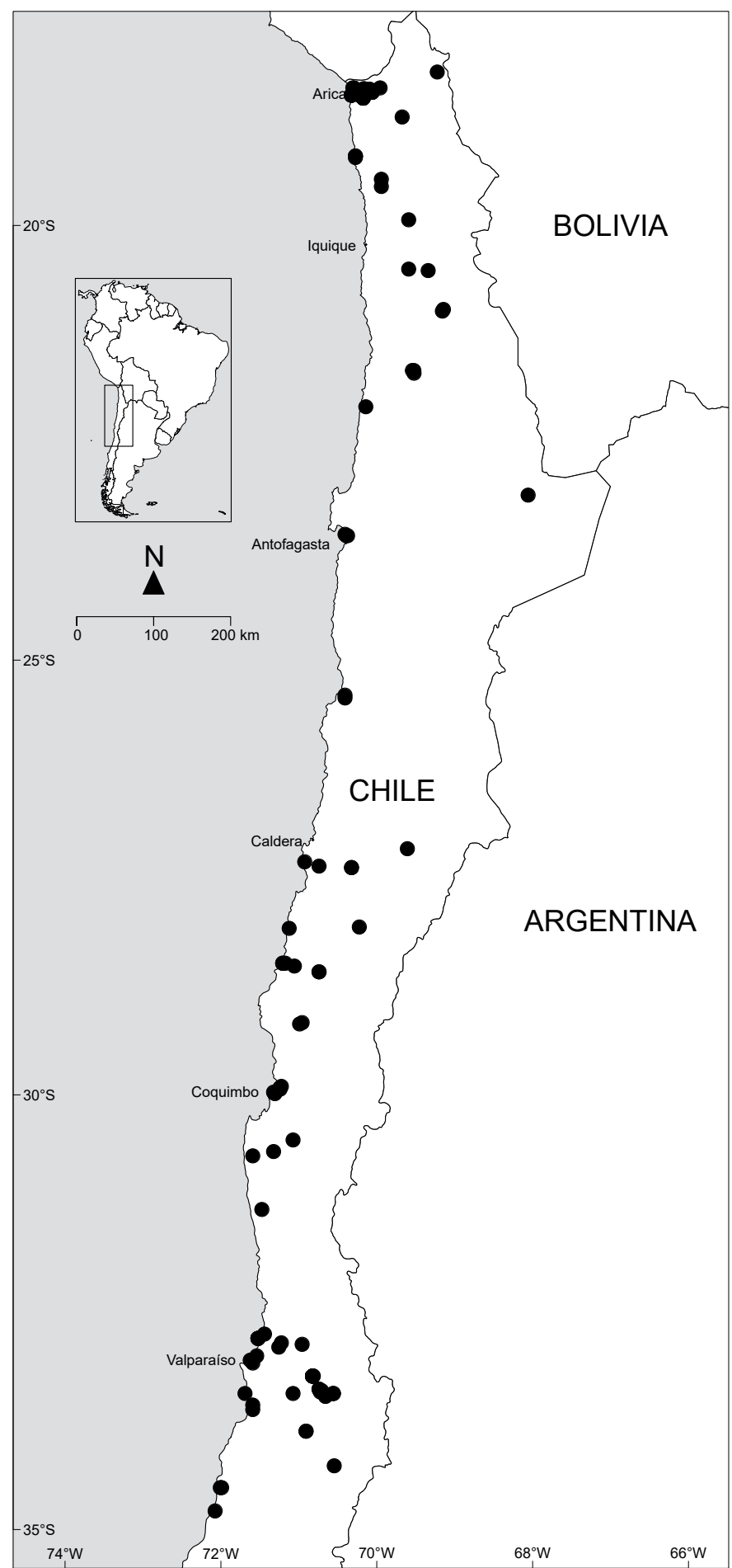

Figura 3. Mapa de distribución de Heliotropium curassavicum en Chile. / Distribution map of Heliotropium curassavicum in Chile. 
Arica, playa Las Machas, 20 m, 18-XII-1996, E. Belmonte y O. Núñez 96549 (CONC); Arica, M. Arriagada s.n. (CONC 99013); camino de Arica al interior del valle de Azapa, km 4, parcela El Teniente, $18^{\circ} 30^{\prime} \mathrm{S}, 70^{\circ} 11^{\prime} \mathrm{W}, 200 \mathrm{~m}, 22-\mathrm{III}-1987$, O. Matthei \& R. Rodríguez 420 (CONC); valle de Azapa, 15IX-1959, G. Montero 6195 (CONC); valle de Azapa, O. Zöllner 7801 (W); Azapa, 150 m, VIII-1925, E. Werdermann 711 (CONC, BM, E, F, GH, K, NY, S, U, US); valle de Azapa, cerca del pueblo, 11-IX-1955, M. Ricardi 3288 (CONC); km 12 Azapa, 2-XII-1981, J. Elorza s.n. (ULS); Azapa, 2-IV-1956, M. Arriagada s.n. (CONC 121901); Azapa near Arica, X-1880, P. Ortega s.n. (GH); Bajos de Timar, 1844'S, 6941'W, 2000 m, 21-VI-1989, E. Belmonte 89-505 (CONC); Qda. Camarones, 24-IX-1955, M. Ricardi 3495 (CONC); quebrada Camarones, 19-I-1971, A. Garaventa 5405 (CONC); valle Camarones, I-1959, E. del Solar s.n. (CONC 99009); desembocadura del Río Camarones, 13-II-1960, V. Behn s.n. (CONC 27883); Región de Tarapacá, Prov. Tamarugal, oasis de Tiliviche, quebrada de Tiliviche, 23-X-1961, A. Garaventa 4473 (CONC); Pisagua-Corza, 11-VIII-1968, J. Chong s.n. (CONC 32726); quebrada Huatacondo, $20.947003^{\circ} \mathrm{S}$, 69.153862 ${ }^{\circ} \mathrm{W}, 1800 \mathrm{~m}, 18-$ III-2017, F. Luebert, T. Böhnert, F.F. Merklinger \& A. Stoll 3543 (BONN); Tamantica, IX-1899, F. Johow s.n. (CONC 99007); Tarapacá, 1955'S, 69³6'W, 1350 m, 29-IV-1994, R. Tapia s.n. (CONC 130557); Los Canchones, $20^{\circ} 29^{\prime} \mathrm{S}, 69^{\circ} 36^{\prime} \mathrm{W}, 970 \mathrm{~m}, 22-\mathrm{IV}-1994$, S. Ramos s.n. (CONC 130566); Pica, III-1885, C. Rahmer s.n. (SGO 42252); "prov. Iquique", X-1881, L. Darapsky s.n. (SGO 42253); Prov. indefinida, s.loc, 1885, F. Philippi s.n. (US 944554); "prov. Tarapacá", III-1885, s.col s.n. (SGO 54409); Región de Antofagasta, Prov. Tocopilla, Quillagua, 23-191996, J. Gutiérrez \& F. López 9 (ULS); Quillagua, 21³9'S, $69^{\circ} 32^{\prime} \mathrm{W}, 850 \mathrm{~m}, 22-\mathrm{IX}-1996$, O. Matthei 441 (CONC); Quillagua, 800 m, 18-I-1970, O. Zöllner 4015 (CONC, W); Quillagua, am Loafluss, 21-I-1970, O. Zöllner s.n. (G);

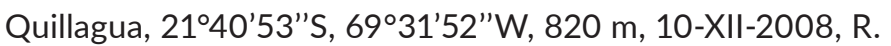
Baines, M. Gardner, P. Hechenleitner, C. Morter \& D. Rae 354 (E); camino a Tocopilla, 2333'S, 70²3'W, 20 m, 29-IX1996, O. Matthei 507 (CONC); Prov. El Loa, Tambillo Chico, III-1885, F. Philippi s.n. (SGO 42265); Prov. Antofagasta, quebrada La Chimba, entre el mar y el desierto, 10-XIII-1948, F. Sudzuki 227 (SGO); La Chimba, huertos del sector Enap, 233'S, 70²4'W, 50 m, 30-IX-1991, M. Quezada \& E. Ruiz 107 (CONC); quebrada San Ramón, ca. 6 km NE Taltal, $25^{\circ} 23^{\prime} \mathrm{S}, 70^{\circ} 25^{\prime} \mathrm{W}, 50-80 \mathrm{~m}, 9-\mathrm{XII}-1987$, M.O. Dillon \& S. Teillier 5209 (BONN, F); Taltal, cerro El Peral, 200 m, 10-IX1936, G. Montero 2969 (CONC, GH); Región de Atacama, Prov. Copiapó, desembocadura Rio Copiapó, 2718's, 7056'W, 2 m, 18-XII-2005, G. Arancio 15490 (ULS); Fundo María Isabel, 105 m, 30-X-1986, E. Bobadilla 3834 (CONC); quebrada Paipote, 279'S, 69³7'W, 1900 m, 7-III-1996, P. Brownless, M.F. Gardner, H.S. Maxwell \& R. Rozzi 587 (E); vicinity of Copiapó, 370 m, 16-XI-1925, I.M. Johnston 5008 (E, GH); vicinity of Copiapó, I-1889, E. Gigoux s.n. (GH); Tierra Amarilla - Las Juntas, quebrada Molle Alto $3 \mathrm{~km}$ nach Abzweigung nach Mina Tres Marías, 970 m, 29-X-1997, C. Ehrhart \& J. Grau 97/1355 (M); Yerba Buena Chica, 25-XII1877, T. King 65 (E); Prov. Huasco, Carrizal Bajo, T. King 72 (E); puerto de Huasco, 1860, H. Volckmann 42 (SGO); Huasco Bajo, al E del puerto, 20-120 m, 11-XII-1941, E. Pisano \& R. Bravo 979 (SGO); Huasco, 2-XI-1930, F. Jaffuel 1187 (GH); Freirina, 27-I-1950, A. Pfister s.n. (CONC 9570); Vallenar, X-1927, B. Claude-Joseph 4989 (US); Vallenar, IX-1928, E. Barros s.n. (CONC 99006); Región de Coquimbo, Prov. Elqui, cuesta Pajonales, 30-I-1971, O. Zöllner s.n. (NY); cuesta Pajonales, lado sur de cuesta antes de subir, $29^{\circ} 10^{\prime} \mathrm{S}, 71^{\circ} 0^{\prime} \mathrm{W}$, 500 m, 13-I-1989, G. Arancio 89009 (ULS); Quebrada Honda, 17-XI-1961, C. Jiles 4009 (CONC); río Elqui, altura La Serena, 3-IV-1993, S. Pizarro 25 (ULS); La Serena, in arenosis, 19-I1883, [F. Philippi] s.n. (GH); La Serena, 15 m, IX-1957, J. Muñoz s.n. (CONC 121900); La Serena, en las calles, 26-XI1935, T. Drahlen s.n. (G); La Serena, II-1930, B. ClaudeJoseph 5436 (US); rocks near shore Coquimbo, 15 m, I-1903, G.T. Hastings 584 (US); estero El Culebrón, IV-1991, G. Arancio 91791 (ULS); Prov. Limarí, Algarrobo, 25-I-1915, R. Ochoa s.n. (CONC 99010); Ovalle, quebrada Ingenio, 2-X1949, C. Jiles 1479 (CONC); Fray Jorge, 19-X-1947, B. Sparre 3140 (S); Prov. Choapa, Puerto Manso, 2-VI-1956, C. Jiles

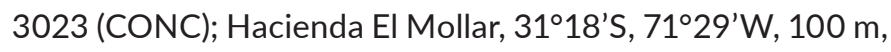
II-1960, S. Lailhacar s.n. (CONC 41308); Región de Valparaíso, Prov. Petorca, Aconcagua-Zapallar, al pie del cerro La Cruz, 20-XII-1916, K. Behn s.n. (CONC 22280); Prov. San Felipe, Llaillay, T. Bridges 318 (BM, E, K); Prov. Quillota, Quillota, 130 m, XI-1961, H. Gunckel 48871 (CONC); Prov. Valparaíso, Quintero, Campiche, II-1962, H. Gunckel 35746 (CONC); Quintero, 21-II-1937, G. Looser 3659 (G, GH); Quintero, I-1961, H. Gunckel 42846 (CONC); Quintero, II-1962, H. Gunckel 46876 (CONC); Quintero, 31-I-1940, G. Looser s.n. (G); Reñaca, playa, 19-X-1936, F. Jaffuel \& A. Pirion 3601 (GH); Valparaíso, a orillas del mar, XI-1912, F. Jaffuel 346 (GH); Valparaíso, Torpedera, 5-II-1932, G. Looser s.n. (CONC 134631, G); Valparaiso bei Viña del Mar, 25 m, XII-1895, O. Buchtien s.n. (US 1134840); Prov. San Antonio, Punta de Tralca, I-1914, E. Barros 806 (CONC); Cartagena, I-1920, B. Claude-Joseph 977 (US); Llolleo, S of San Antonio, 15-I-1952, E.M. Poulsen s.n. (C); Región de Metropolitana de Santiago, Prov. Chacabuco, Batuco, laguna seca, zonas donde se retiró

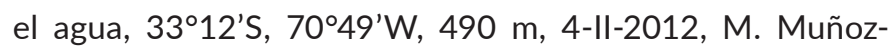
Schick 5331 (BONN, B, SGO); Batuco, I-1932, F. Jaffuel 1783 (GH); Batuco, 10-XII-1928, G. Looser 3301 (G, GH); Batuco, 
en un terraplén artificial, 7-XI-1936, G. Looser 3629 (G, GH); Batuco, 16-IV-1942, H. Gunckel 12884 (CONC); Batuco, 480 m, XI-1950, H. Gunckel 21820 (CONC); Batuco, 450 m, 17III-1955, H. Gunckel 39099 (CONC); Batuco, 480 m, 30-XI1951, H. Gunckel 45406 (CONC); Batuco, 480 m, IX-1955, H. Gunckel 45609 (CONC); Batuco, 1-XI-1913, V. Baeza s.n. (CONC 99008); Prov. Santiago, Santa Luisa, cerca de Quilicura, 450 m, 15-XI-1987, O. Matthei \& M. Quezada 601 (CONC); Quilicura, prope Santiago, s.col s.n. (BM); cerro Renca, F. Philippi s.n. (SGO 42255); plazuela de Renca, II1876, [R.A.] Philippi s.n. (GH); Plazuela de Renca, II-1876, [R.A.] Philippi s.n. (SGO 54413); Santiago, F. Philippi s.n. (SGO 42254); Santiago, "Montaria", 5-XII-1920, B. ClaudeJoseph 1326 (US); Santiago, R.A. Philippi 642 (K, W); "prov. Santiago, in collibus", IX-1831, [C. Gay] 1430 (SGO); Santiago, [Philippi?] s.n. (FI); Prov. Melipilla, fundo Miraflores, comuna Curacaví, 16-III-1967, M. Merino s.n. (SGO 77002-77005); in arenosis prope lacum Aculeo, 1830, C. Bertero 320 (G-DC, P); prope lacum de Aculeo dictum, III-1818, [C. Bertero] s.n. (SGO 54408); Región de O'Higgins, Prov. Cachapoal, [Baños de] Cauquenes, 14-V-1882, J. Ball s.n (E); Prov. Cardenal Caro, Cahuil, 3 m, 23-I-1929, G. Montero 775 (CONC, GH); laguna Cahuil, II-1954, M. Arriagada 7503 (CONC); Llico, XII1861, R.A. Philippi s.n. (SGO 54410); Región indeterminada, near the river Chacayes, Chili, A. Cruckshanks 65 (K); "in Chili ad Cordilleras", 1832, H. Cuming 267 (BM, E, GH, K); "Chili", 19-V-1875, E.C. Reed s.n. (BM); "Chile", H. Cuming s.n. (BM); "Chile", T. Bridges s.n. (K).

Comentarios: Heliotropium curassavicum es miembro de la sección Platygyne, grupo aparentemente compuesto por cinco especies: $H$. curassavicum, $H$. patagonicum, $H$. johnstonii Ragonese, H. ruiz-lealii I.M.Johnst y $H$. spathulatum Rydb. La monofilia de esta sección sólo ha sido parcialmente demostrada (Hilger \& Diane 2003, Luebert et al. 2011), indicando que $H$. curassavicum y $H$. patagonicum están estrechamente relacionadas. La segunda especie había sido previamente asignada a la sección Coeloma (DC.) I.M. Johnst. (Johnston 1928a, Förther 1998). No hay datos moleculares para $H$. johnstonii. Datos moleculares no publicados del autor confirmarían la pertenencia de $\mathrm{H}$. ruiz-lealii y $\mathrm{H}$. spathulatum a la sección Platygyne. La primera de ellas también fue originalmente descrita como miembro de la sección Coeloma, aunque indicando sus posibles afinidades con $\mathrm{H}$. curassavicum (Johnston 1959), mientras que H. spathulatum ha sido considerada por algunos autores como sinónimo de H. curassavicum (e.g., Johnston 1942, 1964).

Tres variedades de Heliotropium curassavicum han sido registradas en Sudamérica: la variedad típica, $H$. curassavicum var. argentinum I.M. Johnst. y H. curassavicum var. fruticulosum
I.M. Johnst. (Johnston 1928a, 1959). Sólo la primera está presente en Chile.

En Chile la especie más estrechamente relacionada es H. patagonicum, perteneciente a la misma sección, de la cual se diferencia por sus hojas lineales o espatuladas versus las hojas orbiculares de $\mathrm{H}$. patagonicum.

El tipótipo (traducción del inglés typotype, ejemplar que sirve de base para una ilustración tipo) de OXF no coincide $100 \%$ con la ilustración pero es casi seguro que es la planta en la que se basó el dibujo.

Bertero (1929) no proporciona una descripción de $H$. chilense, por lo cual se considera un nomen nudum. Sin embargo, dada la localidad y el material al que este nombre debe ser referido no cabe duda que corresponde a un sinónimo de $H$. curassavicum.

Heliotropium geissei F. Phil., Anales Univ. Chile 90: 352. 1895. TIPO: CHILE, Aconcagua, San Lorenzo, s.f., Geisse s.n. (lectotipo, designado por Johnston 1928a: 17 y refinado por Luebert \& Muñoz-Schick 2014: 31-32, SGO 42247!). Sintipos remanentes: CHILE, Aconcagua, San Lorenzo, Geisse s.n. ("1889/1890" SGO 54415! [fototipos: GH!, M!, NY!], "XI.1890" SGO 72734! [fototipo: M!], "XI.1889" SGO 72735! [fototipo: M!]). Prov. Chacabuco, El Alba cerca de Colina, XII-1891, F. Philippi s.n. (SGO 54414!, 42260!, GH! [fragm.]; posible isosintipo: $\mathrm{BM!)}$.

Iconografía: di Fulvio \& Ariza Espinar (2000: 277, fig. 1), Marticorena (1968: 41, fig. 14B [polen]), Navas (1979: 351, lam. 10A-D), Luebert \& Muñoz-Schick (2014: 32-34, figs. 1-3).

Referencias: Reiche (1907: 121; 1910: 195), Johnston (1928a: 17), Navas (1979: 54), di Fulvio \& Ariza Espinar (2000; 2016: 765), Luebert \& Muñoz-Schick (2014), Luebert (2017: 793).

Hierba anual, postrada, 2,5-10(-40) cm de alto, pubescente. Hojas alternas o subopuestas, solitarias o las basales agrupadas en una roseta, pecioladas, pubescentes; peciolo ca. 5-15 mm de largo; lámina orbicular o anchamente elíptica, concolora, con los nervios marcados, 7-15(-17) x 5-10 mm, margen entero, base redondeada o truncada, ápice obtuso o redondeado. Inflorescencias terminales o axilares, simples o dicotómicamente ramificadas hasta en dos niveles, 2-3 $\mathrm{cm}$ de largo. Flores subsésiles, 2,5-3,5 mm de largo. Cáliz persistente, dividido casi hasta la base; sépalos lineallanceolados o lineal-espatulados, densamente pubescentes por fuera, glabros por dentro, ca. $2 \mathrm{~mm}$ de largo, ca. 0,7 mm de ancho en la base, ápice obtuso. Corola hipocrateriforme, blanca con centro amarillento o anaranjado, tornándose violeta en la madurez, 2,5-3,5 mm de largo, ca. 2,5-3 mm de 
diámetro; lóbulos redondeados, ca. $1 \mathrm{~mm}$ de diámetro; tubo pubescente en las nervaduras por fuera, glabro por dentro. Estambres inclusos; filamentos adnados a los pétalos; anteras libres, aovado-lanceoladas, ca. $1 \mathrm{~mm}$, base redondeada, cordada, localizada aproximadamente sobre la porción receptiva de la columna estigmática a cerca de $1 / 3$ de la base del tubo; ápice acuminado, papiloso. Ovario glabro, ca. 0.5 $\mathrm{mm}$ de alto, ca. $0.6 \mathrm{~mm}$ de diámetro, con disco nectarífero poco o muy desarrollado en la base. Estilo inconspicuo. Columna estigmática cónica, 0,4-0,5 mm de largo, ca. 0,3$0,5 \mathrm{~mm}$ de ancho en la base, laxamente pubescente. Frutos secos, pubescentes, ca. 1-1,3 x 1,2-1,5 mm, separándose en 4 nueces uniseminadas. Nueces sin cavidades vacías, superficie dorsal lisa, conspicuamente papilosa.

Distribución: Crece sobre suelos salinos de la depresión intermedia de Chile central en las provincias de Chacabuco (Región Metropolitana) y de Petorca (Región de Valparaíso). Di Fulvio \& Ariza Espinar (2000) reportan la presencia de esta especie en Argentina (provincia de Mendoza, departamento Malargüe) (Fig. 4).

Especímenes examinados: CHILE. Región Metropolitana. Prov. Chacabuco, Colina, tranque Las Tórtolas, I-1997, S. Teillier 3907 (SGO); hacienda Santa Filomena, 33¹1'14"S, 71'18'00"W, 1780 m, 22-I-2012, M. Muñoz \& V. Morales 5307 (SGO, B); 1-II-2012, A. Moreira \& M. Muñoz 1797 (SGO, B, BONN); Batuco, XI-1913, V. Baeza s.n. (CONC 46434, 121914, GH); Batuco, 480 m, 10-I-1950, H. Gunckel 20565 (CONC); Batuco, 4-IV-1954, M. Arriagada s.n. (CONC 121910); Batuco, 480 m, 6-XI-1954, H. Gunckel 26795 (CONC); Batuco, 6-XI-1954, B. Sparre 10982 (CONC); laguna seca de Batuco, I-1909, K. Reiche (SGO 61317); Batuco, laguna seca 33¹2'56.3"S, 7049'24.3"W, 490 m, 4-II-2012, M. Muñoz \& V. Morales 5330 (SGO, B); cuesta Chacabuco, 26-XI-1969, M. Mahu s.n. (H 1211658); cuesta Chacabuco, 12-XI-1970, M. Mahu s.n. (H 1211654).

Comentarios: Estudios moleculares recientes (Luebert \& Muñoz-Schick 2014) confirman la pertenencia de esta especie a la sección Plagiomeris, tal como había sido planteado por Johnston (1928a) y Förther (1998), descartando su afinidad con las especies de Heliotropium del Viejo Mundo, idea que llevó a Reiche $(1907,1910)$ a plantear que podría tratarse de una especie introducida.

Muy afín a Heliotropium paronychioides, de la cual se diferencia por las láminas orbiculares o anchamente elípticas y por las papilas digitiformes sobre la superficie dorsal de las nueces, versus las hojas angostamente elípticas y las nueces glabras o con pubescencia laxa simple de $\mathrm{H}$. paronychioides. Véase di Fulvio \& Ariza Espinar (2000).

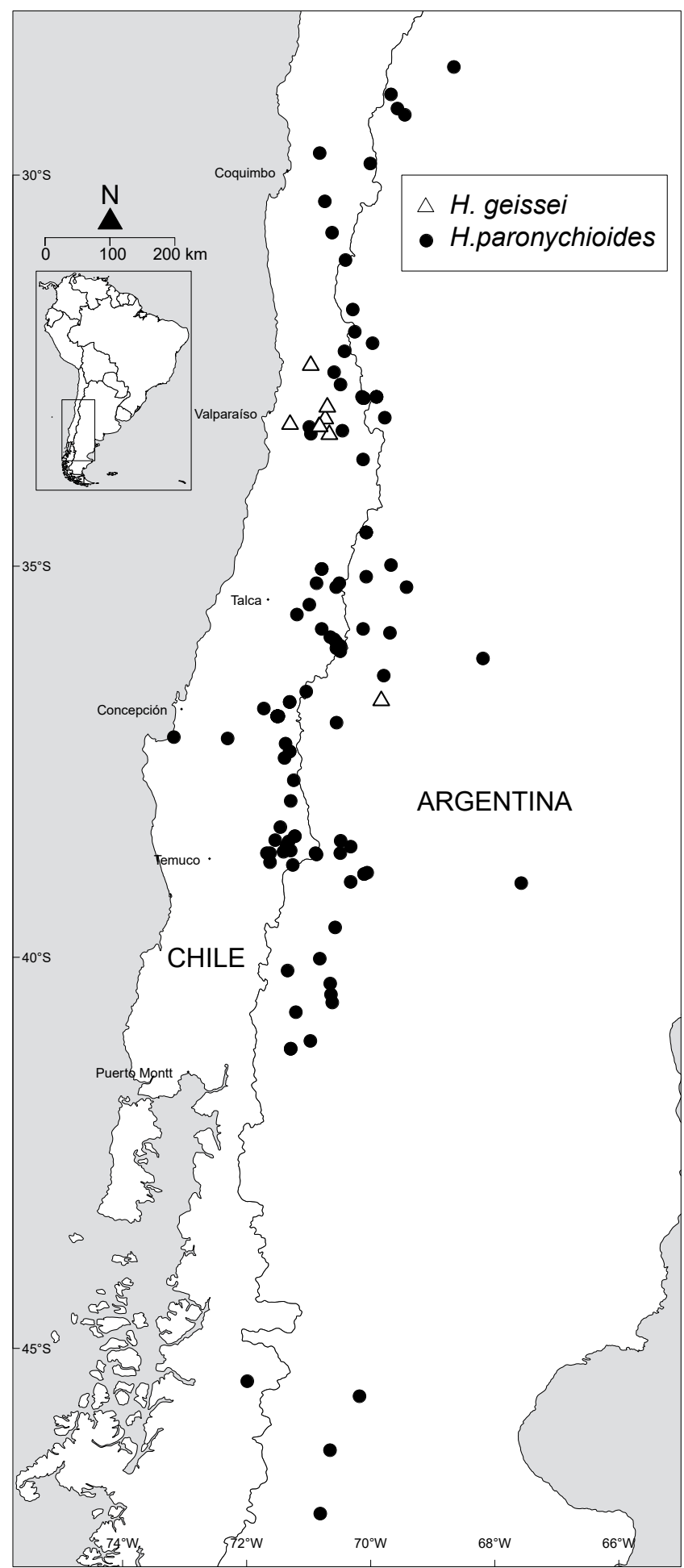

Figura 4. Mapa de distribución de Heliotropium geissei (triángulos) y H. paronychioides (círculos). Además de los ejemplares examinados se utilizó información de localidades de di Fulvio \& Ariza Espinar (2000, 2016). / Distribution map of Heliotropium geissei (triangles) and $H$. paronychioides (circles). Apart from the examined specimens, locality information from di Fulvio \& Ariza Espinar (2000, 2016) was employed. 
Tal como se indica en Luebert \& Muñoz-Schick (2014), no es posible establecer que todos los materiales tipo recolectados por Geisse en la localidad de San Lorenzo corresponden a duplicados de la misma colección. Por esta razón los materiales que no pertenecen al lectotipo se clasifican como sintipos y no como isotipos.

Heliotropium microstachyum Ruiz \& Pav., Fl. Peruv. [Ruiz \& Pavón] 2: 3, t. 110. 1799. TIPO: Tarma, I-1780, [H. Ruiz \& J Pavón s.n.] (lectotipo, designado por Luebert \& Hilger 2014: 3, MA [MA814829]!; isolectotipos $\mathrm{B} \dagger$ [F neg. nr. 17333!], FI-W[FI 004998]!, MA[MA814831, MA814832]!; posibles isolectotipos B-WILLD 3237!, F 842502!, G [Herb. Boissier]!, M[M0188668]!, MPU[MPU019717], P[P00610207]!, S S-R2846!, Dombey s.n., P[P00610206]!, fototipo MSB!, Dombey 366, G-DC[G00148000]!, L[L0004005]!, M[M0188054]!, $\mathrm{P}[\mathrm{P03877800]!).}$

Heliotropium bangii Rusby, Bull. New York Bot. Gard. 4: 414. 1907. TIPO: Bolivia, 1891, M. Bang 2847 (holotipo, NY[NY00335386]!; isotipos F[F0052469F] fototipo!, GH[GH00097600]!, K[K000583567]!, NY[NY00335387]!, MICH[MICH1111503] fototipo!, PH[PH00026058] fototipo!, US[US00110842! US00512993!], WIS[WISv0255175] fototipo!).

Heliotropium brachystachyum (DC.) Griseb., Abh. Königl. Ges. Wiss. Göttingen 24: 271. 1879. Heliophytum brachystachyum DC., Prodr. (DC.) 9: 554. 1845. TIPO: in Peruvia, J. Dombey 366 (holotipo, G-DC[G00148000]!; isotipos L[L0004005]!, $\mathrm{M}[\mathrm{M} 0188054]$ !, $\mathrm{P}[\mathrm{P03877800]!}$ [foto MSB!], posible isotipo J. Dombey P[P00610206]!).

Heliotropium phaenocarpum (Phil.) Reiche, Anales Univ. Chile 121: 237. 1907. Coldenia phaenocarpa Phil., Anales Mus. Nac. Santiago de Chile sect. 2 Bot. 8: 56. 1891. TIPO: Bolivia, Calchaguay, 28-I-1886, C. Rahmer s.n. (lectotipo, designado por Förther 1998: 229, SGO 54429! [foto MSB!]; isolectotipos SGO 42228! [foto MSB!], GH[GH00094701], K!).

Lithospermum aggregatum Ruiz \& Pav., Fl. Peruv. [Ruiz \& Pavón] 2: 4. 1799. TIPO: "Heliotropium aggregatum" Cheuchín et Tarma (lectotipo, designado por Luebert \& Hilger 2014: 4, MA[MA814830]!; posible isolectotipo P[P00610208]!).

Iconografía: Ruiz \& Pavón (1799: t. 110a¹), Gangui (1955: 507,

${ }^{1}$ En la referencia original (Ruiz \& Pavón 1799), la figura aparece erróneamente citada como t. 110b. Este error ha sido advertido al menos desde de Candolle (1845: 550, nota 1). fig. 3D-H), Pérez-Moreau \& Cabrera (1983: 268, fig. 108), Pérez-Moreau et al. (2017: 54, fig. 26).

Referencias: Reiche (1907: 121; 1910: 195, sub $H$. phaenocarpum), Johnston (1928a: 12), Gangui (1955: 505), Macbride (1960: 563), Pérez-Moreau \& Cabrera (1983: 267), di Fulvio \& Ariza Espinar (2016: 772), Luebert (2017: 792), Pérez-Moreau et al. (2017: 53).

Hierba perenne, con raíz gruesa, postrada, de hasta $30 \mathrm{~cm}$ de diámetro, pubescente. Hojas subopuestas, solitarias, pecioladas, pubescentes; peciolo 1-10 mm de largo; lámina elíptica a oval-lanceolada, concolora, con los nervios marcados, 1-30(-45) x 2-15(-25) mm, margen entero, revoluto, base atenuada, ápice obtuso. Inflorescencias terminales o axilares, simples, glomeruliformes, paucifloras, de hasta 10$15 \mathrm{~mm}$ de diámetro. Flores subsésiles, 2-2,5 mm de largo. Cáliz persistente, dividido hasta la base; sépalos oblongoaovados, laxamente pubescentes por fuera y glabros por dentro, de ca. 1,5 mm de largo, ca. 0,5 mm de ancho en la base, ápice obtuso o truncado. Corola infundibuliforme, blanca o lila, 1,5-2,5 mm de largo, ca. 0,5-1 mm de diámetro; lóbulos redondeados a ovales, ca. 0,5 mm de diámetro; tubo glabro en ambas caras. Estambres inclusos; filamentos adnados a los pétalos; anteras libres, aovadas, ca. 0,3-0,4 mm de largo, base cordada, localizada aproximadamente sobre la porción receptiva de la columna estigmática en la mitad del tubo; ápice obtuso, no papiloso. Ovario glabro, ca. 0,5 $\mathrm{mm}$ de alto, ca. 0,5 mm de diámetro, con disco nectarífero poco desarrollado en la base. Estilo inconspicuo. Columna estigmática cónica, ca. 0,2 mm de largo, ca. 0,2 mm de ancho en la base, glabra. Frutos secos, laxamente pubescentes, café claros, ca. 1,8 $\times 2,3 \mathrm{~mm}$ separándose en 2 nueces biseminadas o más frecuentemente uniseminadas por aborto. Nueces sin cavidades vacías, superficie dorsal ligeramente rugosa.

Distribución: Especie altoandina, tropical. Se distribuye desde el centro de Ecuador hasta el norte de Chile y Argentina, frecuente entre 2000 y 4000 m de altitud (Fig. 5). Sólo se conocen tres ejemplares chilenos.

Especímenes examinados: ECUADOR. Prov. Pichincha, Vía Mitad del Mundo-Calacalí, a $500 \mathrm{~m}$ de monumento a la Mitad del Mundo, 7-IV-1979, J. Jaramillo \& S. Keel 917 (AAU); Pomasqui, 15-V-1931, R. Benoist 4292 (P); Prov. Chimborazo, Riobamba, XI-1858, R. Spruce 5778 (BM, E, G, K, M, P, S, W); Chambo, 2800 m, 10-V-1939, E. Asplund 5949 (G, K, P, S). Prov. Indefinida, Interandine highland, $2800 \mathrm{~m}$, V-1932, A. Rimbach 435 (S). 


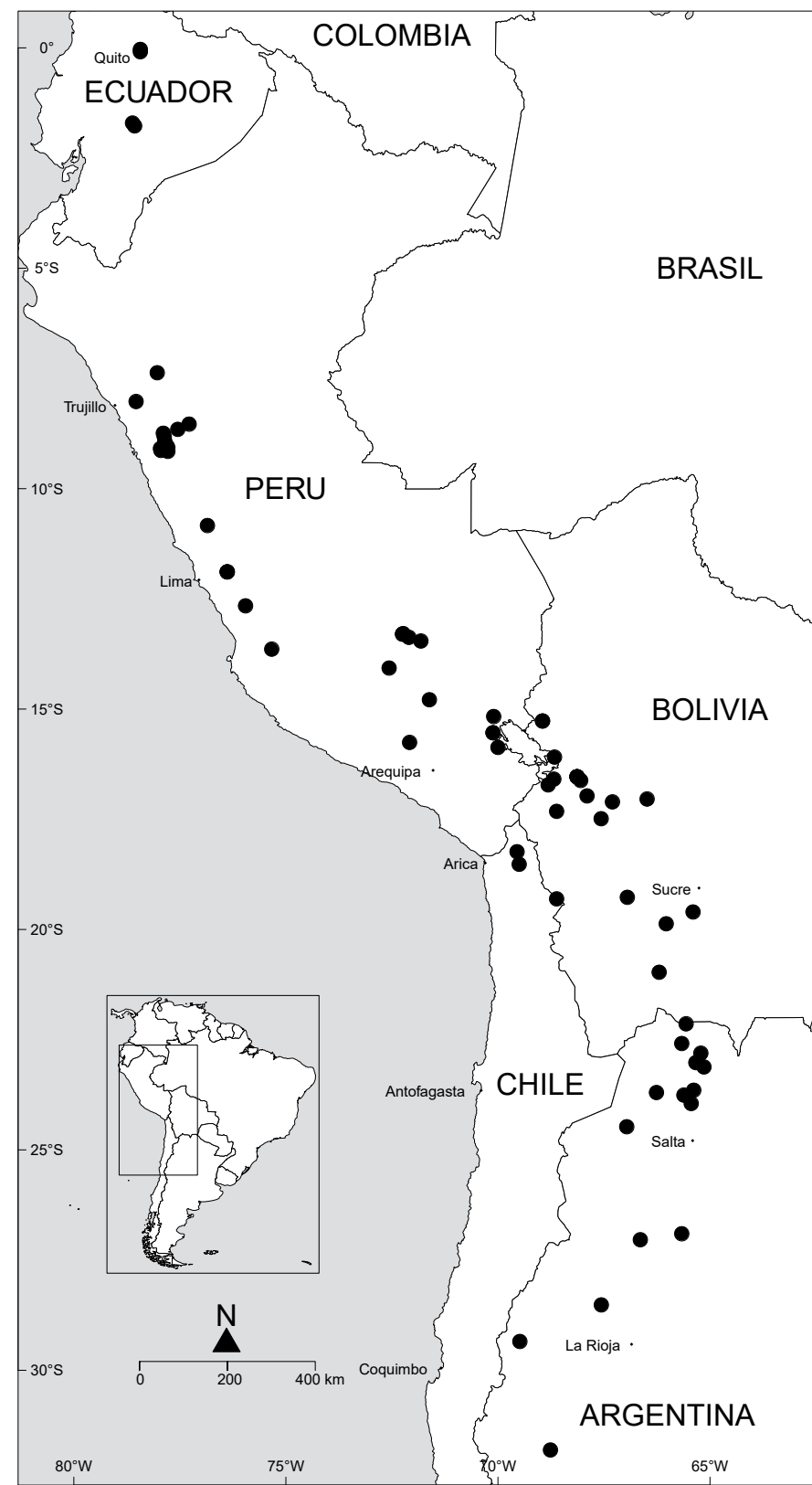

Figura 5. Mapa de distribución de Heliotropium microstachyum. Además de los ejemplares examinados se utilizó información de localidades de di Fulvio \& Ariza Espinar (2016). / Distribution map of Heliotropium microstachyum. Apart from the examined specimens, locality information from di Fulvio \& Ariza Espinar (2016) was employed.

PERÚ. Depto. Cajamarca, road Cajamarca-Cajabamba, 18 km from Cajabamba, 2150-2200 m, II-IV-1997, M. Weigend, N. Dostert \& K. Drießle 97/320 (BONN, MSB); Depto. La Libertad, Los Hornos (abajo Agallpampa), 2500 m, 28-III1991, R. Campos, C. Corritti, P. Lezama \& C. Tellez 14438
(MSB); road Huancaspata to Sihuas (Ancash), descent towards the Marañón river, $8^{\circ} 30^{\prime} \mathrm{S}, 77^{\circ} 17^{\prime} \mathrm{W}, 2714 \mathrm{~m}, 25$-IV2004, M. Weigend \& C. Schwarzer 8023 (B); Depto. Ancash, road Sihuas-Sicsibamba along Río Sihuas, 2600-2800 m, 11III-2001, M. Weigend, K. Weigend, M. Binder \& E. Rodríguez 5090 (BONN, M); road Sihuas to Corongo/Mirador (on Río Santa), 842'S, 7754'W, 2222 m, 26-IV-2004, M. Weigend \& C. Schwarzer 8044 (B, M); road from Caraz to Santa, cañón de Santa, 847'S, 7753'W, 1261 m, 29-IV-2006, M. Weigend, C. Schwarzer, G. Brokamp \& T. Henning 8504 (M); cordillera Negra, $29.4 \mathrm{~km}$ from Caraz on road to Huaylas, $8^{\circ} 53^{\prime} \mathrm{S}, 77^{\circ} 52^{\prime} \mathrm{W}, 2763 \mathrm{~m}, 29-\mathrm{IV}-2004, \mathrm{M}$. Weigend \& C. Schwarzer 8050 (B, M); road Caraz-Pamparomás, 859'S, 77²9'W, 1124 m, 28-IV-2006, M. Weigend, C. Schwarzer, G. Brokamp \& T. Henning 8500 (M); $5 \mathrm{~km}$ after Caraz on road to Casma, 2200 m, 14-V-2003, M. Weigend, T. Henning \& O. Mohr 7658 (B); road Karka-Pamparomás, 9³'S, 7758'W, 2850 m, 26-X-2000, M. Weigend, H. Förther \& N. Dostert 2000/970 (MSB); road from Pamparomás to Caraz, 95'S, 7757'W, 3321 m, 27-IV-2006, M. Weigend, C. Schwarzer, G. Brokamp \& T. Henning 8480 (BONN, M); cerro Yanyaco (Pueblo Libre), 2500-3030 m, 9-I-1995, A. Cano \& J. Roque 6337 (MSB); Depto. Lima, Baños de Churín, 2590 m, Il-1946, C. Sandeman 5409 (K); Matucana, 2440 m, IV-V-1922, J.F. Macbride \& W. Featherstone 202 (S); Matucana, Andes Peruvianus, 1876-1879, L. Savatier 546 (K); Matucana, 2400 $\mathrm{m}, 25-\mathrm{V}-1940$, E. Asplund 11094 (S); road from Yauyos to Imperial, km 25,7 after Yauyos, $1^{\circ}{ }^{\circ} 37^{\prime} \mathrm{S}, 7^{\circ} 5^{\circ} 8^{\prime} \mathrm{W}, 1750 \mathrm{~m}$, 8-X-2002, M. Weigend, A. Ackermann. A. Cano \& M.I. La Torre 7314 (B); Depto. Huancavélica, Huaytará, 2600-2700 m, V-1910, A. Weberbauer 5427 (MSB); Depto. Cusco, ruins of Ollantaytambo, $13^{\circ} 15^{\prime} \mathrm{S}, 72^{\circ} 15^{\prime} \mathrm{W}, 2860 \mathrm{~m}, 1-\mathrm{IV}-2009$, M. Ackermann 755 (BONN); Ollantaytambo, $13^{\circ} 15^{\prime} \mathrm{S}, 72^{\circ} 15^{\prime} \mathrm{W}$, 2858 m, 2-IV-2009, M. Ackermann 763 (BONN); Urubamba valley, Inca ruins of Ollantaytambo, 27-IX-2001, H.H. Hilger 2001/10 (BONN); road Chinchero-Urubamba, 3200-3500 m, 5-II-2000, M. Weigend \& K. Weigend 2000/160 (M); Pisac, 3000 m, III-1943, F. Marín 178 (W); Coporaque, 4000$4011 \mathrm{~m}$, 5-XII-2009, A. Cano, H. Trinidad \& N. Valencia 19548 (BONN); Kayra, 3100 m, I-1938, C. Vargas 654 (MSB); Chuyani, right bank of the Apurimac river, $2850 \mathrm{~m}$, 6-I-1939, C. Vargas 9726 (G, K); Depto. Apúrimac, hacienda Lucre, Oropeza valley, 2600 m, 17-I-1939, C. Vargas 9759 (K); Depto. Arequipa, curves Cabanacombe-Huambo, 3550 m, 6-III-1980, R. Lilljekvist 80 (C); Depto. Puno, Arapa, 3900 m, 18-II-1948, P. Aguilar 107 (MSB); Juliaca, 3810 m, 29-I1957, D. Stafford 453 (BM, K); road Juliaca-Pucará, a short way behind Juliaca, 3800-3900 m, 28-I-2000, M. Weigend \& K. Weigend 2000/30 (M); Titicaca See, am Hotel, I-1975, W. Schwabe s.n. (B). 
BOLIVIA. Depto. La Paz, Amarete, 3750 m, 31-I-1980, J. Krach 7810 (M); Amarete, 3700 m, 30-I-1980, J. Krach 8260 (M); viciniis Achacachi, 4000 m, I-III-1859, G. Mandon 384 (BM, G, K, P, W); La Paz, 3750 m, 28-I-1907, O. Buchttien 121 (W); La Paz, 3700 m, 22-X-1920, E. Asplund 530 (S); La Paz, 14-IV-1880, O. Buchttien 604 (B, C, CONC, M, S); La Paz, 3500 m, III-1918, O. Buchtien 3990 (S); Chivesivi - valle de La Paz, 2590-3660 m, 1839, M. Pentland s.n. (P P03877044); near La Paz, 3048 m, X-1885, H.H. Rusby 2539 (MSB); Tiahuanaco, 22-I-1903, A.W. Hill 327 (K); comunidad Titicani-Tacaca, a $20 \mathrm{~km}$ de Guaqui, 3870-3970 m, 10-IV1989, X. Villavicencio 698 (B); Urmiri, $16^{\circ} 56^{\prime} \mathrm{S}, 67^{\circ} 55^{\prime} \mathrm{W}$, 4000 m, 27-III-1999, S. Beck 22978 (M); valle de Luribay, 17'4'S, 67019'W, 2500 m, 5-IV-1994, S. Beck 119PG94 (MSB); Calacoto, 3800 m, 5-XI-1920, E. Asplund 704 (S); La Paz-Calacoto, al sur del río Huañajahuira, 4-XI-1979, S. Beck 2357 (M); Muela del Diablo, 3800 m, 4-III-1995, I. Hensen s.n. (MSB); Depto. Cochabamba, Choró. Above the Cocapata River about 100 miles NW of Cochabamba, across the Tunari range, $17^{\circ} 0^{\prime} \mathrm{S}, 66^{\circ} 30^{\prime} \mathrm{W}, 3-1 \mathrm{l}-1950$, W.M.A. Brooke 6097 (BM); Depto. Oruro, Quiliacas [Quillacas?], 3800 m, 29-XII1926, C. Troll 3016 (M); Huancaima?, 3800 m, II-1934, C. Hammarlund 121 (S); Depto. Potosí, cerro Tomillque, near Betanzos, 3500 m, 3-II-1994, J.R.I. Wood 7897 (K); between La Palca and Cayara, 3500 m, 27-XII-1994, J.R.I. Wood 9015 (K); Atocha, 3700 m, 20-III-1921, E. Asplund 3018 (S); Depto. Indefinido, M. Bang 1971 (BM, G, K, M, W).

CHILE. Región de Arica y Parinacota, Prov. Parinacota, cerca de Putre, $18^{\circ} 12^{\prime} \mathrm{S}, 6^{\circ} 34^{\prime} \mathrm{W}, 3300-3450 \mathrm{~m}, 2-11 \mathrm{l}-1984$, M.T.K. Arroyo 84-584-A (CONC); Belén, $18^{\circ} 29^{\prime} \mathrm{S}, 6^{\circ} 31^{\prime} \mathrm{W}$, 3420 m, 14-XI-1974, J. Castillo s.n. (CONC 55637); Región de Tarapacá, Prov. Tamarugal, Colchane, $19^{\circ} 16^{\prime} \mathrm{S}, 68^{\circ} 38^{\prime} \mathrm{W}$, 3720 m, 21-III-1982, C. Villagrán \& M.T.K. Arroyo 4146 (CONC).

ARGENTINA. Prov. Jujuy, Depto. Cochinoca, RN9, $1 \mathrm{~km} \mathrm{~S}$ puesto del Marqués (18 km N Abra Pampa), 3490 m, 11-XII1995, H.H. Hilger, D. Medán \& G. Roitman ARG95/54 (B, BONN, MSB); Depto. Humahuaca, Ruta 13, Iturbe, 3342 m, 19-III-1982, A. Schinini \& R. Vanni 22556 (C); Depto. Tumbaya, quebrada Huachichocana, 2700 m, 14-II-1963, A.L. Cabrera, E. Ancibor, R.R. Ré, H. Tello \& A. Torres 15023 (M); Provincia Salta, Depto. Iruya, Iruya, camino a la cruz, al SW del pueblo, 2800 m, 23-III-1989, L. Novara, T. Osten \& H. Suligoy 8719 (G); Depto. Rosario de Lerma, 58 km SE of San Antonio de Los Cobres, towards Salta, road km 103, 2-XII1998, B.E. Leuenberger, U. Eggli \& S. Arroyo-Leuenberger 4613 (B); Depto. Cachi, 46 km de Cachi, camino a Salta, 3050 m, 17-III-1972, A. Krapovicas, V. Murañac, O. Oliva \& H. Pueyo 21978 (G); RN 33 a 6 km E Piedras de Molina, 3400 m, 12-XII-1995, H.H. Hilger, D. Medán \& G. Roitman ARG95/61
(BONN, MSB); Provincia Tucumán, Tafí, 2000 m, 7-III-1903, M. Lillo 3106 (MSB); Provincia Catamarca, Las Minas, 3-III1916, P. Jörgensen 1724 (MSB, U).

Comentarios: La presencia de esta especie en Chile fue establecida por Arroyo \& Marticorena (1985), sobre la base de colecciones aquí examinadas. También aparece en el catálogo de Marticorena \& Quezada (1985). Sin embargo, no está citada para Chile en Zuloaga et al. (2008) ni en Muñoz-Schick \& Morales (2013) y tampoco en Rodríguez et al. (2018). El material citado arriba para Chile no puede ser referido a otra especie. No hay otra especie de Heliotropium en Chile de distribución andina tropical y es la única hierba perenne con frutos que se separan en dos nueces.

Heliotropium paronychioides A.DC., Prodr. 9:565.1845. TIPO: Chili, T. Bridges s.n. (lectotipo, designado por Förther (1998: 211), G-DC[G00147493]!; isolectotipos G[G00177391]!, K[K000583556]!. Sintipos remanentes: Chile, Cordillera, 1842, T. Bridges 1255 (BM!, C!, E[E00143760]!, F[F0052486F] fototipo!, G!, GH[GH00097765]!, K[K000583616]!, P[P00610215]!, SI[SI047772] fototipo!, W 0012892!)

Iconografía: Correa (1999: 139, fig. 95), Gangui (1955: 519, fig. 6F-H), Marticorena (1968: 43, fig. 15A [polen]), Luebert \& Muñoz-Schick (2014: 33, fig. 2), Pérez-Moreau et al. (2017: 53, fig. 25).

Referencias: Reiche (1907: 120; 1910: 194), Macloskie et al. (1914: 212), Johnston (1928a: 17), Gangui (1955: 517), Correa (1999: 133), di Fulvio \& Ariza Espinar (2016; 775), Luebert (2017: 793), Pérez-Moreau et al. (2017: 53).

Hierba anual, efímera, postrada, de $5-25 \mathrm{~cm}$ de diámetro, pubescente. Hojas alternas o subopuestas, solitarias, pecioladas, pubescentes; peciolo (1-)3(-5) $\mathrm{mm}$ de largo; lámina elíptica a lineal-lanceolada, concolora, con los nervios marcados, 5-10(-16) x 1-3(-5) mm, margen entero, ligeramente revoluto, base atenuada, ápice obtuso. Inflorescencias terminales o axilares, simples o dicotómicamente ramificadas hasta en 1 nivel, de 0,8-1,4(-2,5) cm de largo. Flores subsésiles, 1-2 mm de largo. Cáliz persistente, dividido hasta ca. 2/3 de su largo; sépalos aovados o elípticos, pubescentes por fuera, glabros por dentro, ca. 1-1,3 mm de largo, ca. 0,3-0,6 mm de ancho en la base, ápice obtuso. Corola infundibuliforme, blanca con centro amarillo, 1-2 mm de largo, ca. 0,3-0,7 $\mathrm{mm}$ de diámetro; lóbulos redondeados a oblongos, ca. 0,3 $\mathrm{mm}$ de diámetro; tubo glabro en ambas caras o laxamente pubescente por fuera. Estambres inclusos; filamentos adnados a los pétalos; anteras libres, aovadas, ca. 0,25 mm 
de largo, base cordada, localizada aproximadamente sobre la porción receptiva de la columna estigmática a cerca de 1/2-1/3 de la base del tubo; ápice apiculado, no papiloso. Ovario glabro, ca. 0,25-0,6 mm de alto y diámetro, con disco nectarífero poco desarrollado en la base. Estilo inconspicuo. Columna estigmática cónica, ca. 0,2-0,5 mm de largo, ca. $0,4 \mathrm{~mm}$ de ancho en la base, glabra. Frutos secos, glabros o laxamente pubescentes, ca. $1 \mathrm{~mm}$ de diámetro, separándose en 4 nueces uniseminadas. Nueces sin cavidades vacías, superficie dorsal lisa o ligeramente rugosa.

Distribución: Patagonia occidental y Andes del centro y sur de Chile y Argentina, generalmente en bordes de sitios húmedos, entre (100)600 y 3900 m (Fig. 4). En Chile se encuentra principalmente en la cordillera de los Andes entre las regiones de Coquimbo y Aisén, pero también se la ha recolectado en algunos sectores de la cordillera de la Costa de la Región Metropolitana, como en el cordón de Chicauma (García 2010) y los altos de Lipangue, y, también, en la costa e interior de la Región del Biobío.

Especímenes examinados: ARGENTINA, Prov. San Juan, Depto. Iglesia, Arroyo Tambillos, along trail from paso de Valeriano, $28^{\circ} 57^{\prime} \mathrm{S}, 69^{\circ} 41^{\prime} \mathrm{W}, 3900 \mathrm{~m}, 10-\mathrm{I}-1926$, I.M. Johnston 6098 (E, F, K, M, W); Prov. Mendoza, Depto. Las Heras, Puente del Inca, in vecinis montis Aconcagua, 31-I1903, G.O.A. Malme 2861 (S); Puente del Inca, in vecinis montis Aconcagua, 2-II-1903, G.O.A. Malme 2861a (G, S); Puente del Inca, in vecinis montis Aconcagua, 18-II-1903, G.O.A. Malme 2861b (S); Andes de Mendoza, río de Plomo, I-1910, L. Hauman 273 (G); Depto. San Rafael, Atuel valley, near the outlet of Arroyo Largo, 2000 m, 20-XI-1955, T.W. Böcher, J.P. Hjerting \& K. Rahn 1065 (C); Atuel valley above campamento Atuel, 2800 m, 29-XII-1955, T.W. Böcher, J.P. Hjerting \& K. Rahn 1950 (C); alto valle del Atuel, 2300 m, 5-II-1955, A. Ruiz-Leal 16853 (MSB); arroyo Manga, 1800 m, I-II-1897, E. Wilczek 395 (G); Depto. Cuyo, RP222, 3 km E Las Leñas, 2140 m, 17-XII-1995, H.H. Hilger, D. Medán \& G. Roitman ARG95/83 (B, BONN, MSB); Depto. Malargüe, Bombas y Río Salado, Andes y Mendoza, J. Gillies s.n. (K); Malargüe-Las Loicas, 1400-1750 m, 29-I-1994, C. Villagrán, F. Hinojosa \& R. Villa 8065 (CONC); RN40, 7 km N Bardas Blancas, 1590 m, 17-XII-1995, H.H. Hilger, D. Medán \& G. Roitman ARG95/90 (B, BONN, MSB); Prov. Neuquén, Depto. Picunches ca. $0,5 \mathrm{~km} \mathrm{~S}$ of Codihué (quebrada Codihué), $38^{\circ} 29^{\prime} \mathrm{S}, 70^{\circ} 29^{\prime} \mathrm{W}, 825 \mathrm{~m}, 16-\mathrm{I}-2002$, M. Weigend, H. Förther, N. Dostert \& K. Weigend 6916 (BONN, MSB); RN 40, $3 \mathrm{~km} \mathrm{~S} \mathrm{Las} \mathrm{Lajas,} 800$ m, 18-XII-1995, H.H. Hilger, D. Medán \& G. Roitman ARG 95/96 (B, BONN, MSB); Las Lajitas, 1067 m, 5-XII-1925, H.F. Comber 231 (K); Pino Hachado,
5-III-1939, A. Burkart 9622 (SGO); Depto. Zapala, Zapala, 1005 m, XI-1925, H.F. Comber 156 (E, K); Zapala, 3855'S, 707'W, 1050 m, 20-III-1970, H. Roivainen 2771 (H); Zapala, 38 $55^{\prime}$ 'S, 707'W, 1050 m, 20-III-1970, H. Roivainen 2772 (H); Depto. Catán Lil, laguna Blanca, near the lake on E corner, 1350 m, 15-I-2002, M. Weigend, H. Förther, N. Dostert \& K. Weigend 6907 (BONN, MSB); RP 42 (von der RN 40 nach Las Coloradas), 3 km N Brücke río Catán Lil, 900 m, 18-XII-1995, H.H. Hilger, D. Medán \& G. Roitman ARG95/99 (BONN, MSB); Depto. Huiliches, road Junín de Los Andes to Zapala, near La Rinconada, 3959'S, 7049'W, 662 m, 15-I-2002, M. Weigend, H. Förther, N. Dostert \& K. Weigend 6895 (BONN, MSB); Depto. Lácar, San Martín de los Andes, 10-I-1945, C.H. O'Donell 2408 (S); pampa de Alicura, between Confluencia and Alicura, $40^{\circ} 27^{\prime} \mathrm{S}, 70^{\circ} 39^{\prime} \mathrm{W}, 812 \mathrm{~m}, 13-\mathrm{I}-2002$, M. Weigend, H. Förther, N. Dostert \& K. Weigend 6867 (BONN, MSB, W); Depto. Collón Curá, RN40, 2.5 km before Cerrito Peñón, 40¹8'S, 70³9'W, 622 m, 13-I-2002, M. Weigend, H. Förther, N. Dostert \& K. Weigend 6873 (BONN, MSB); Depto. Los Lagos, La Primavera, 21-XI-1937, A. Kalela 959 (H); Prov. Río Negro, Depto. General Roca, vicinity of Gral. Roca, 1914-1915, W. Fischer 264 (BM, K); Depto. Pilcaniyeu, road from San Carlos de Bariloche to Comallo, near lago

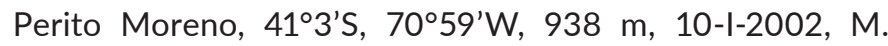
Weigend, H. Förther \& K. Weigend 6819 (BM, BONN, MSB, W); Depto. Bariloche, San Carlos de Bariloche, 800 m, 7-II1905, O. Buchtien 4255 (M, P, S); lago Nahuelhuapi, San Carlos de Bariloche, 800 m, 5-II-1905, O. Buchtien s.n. (H, S 1535764); Prov. Chubut, Depto. Sarmiento, Sarmiento to Río

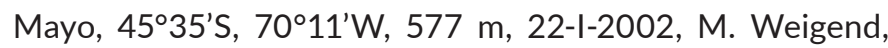
H. Förther, N. Dostert \& K. Weigend 6954 (BONN, MSB); Prov. Santa Cruz, Depto. Lago Buenos Aires, Nacimiento, 24-I-1938, A. Kalela 1975 (H); Depto. Rio Chico, RN 40 N from (Calafate-) Bajo Caracoles-Perito Moreno, $1 \mathrm{~km}$ after camping site río Ecker towards río Pintura, $47^{\circ} 5^{\prime} \mathrm{S}, 70^{\circ} 49^{\prime} \mathrm{W}$, 688 m, 26-I-2002, M. Weigend, H. Förther, N. Dostert \& K. Weigend 6996a (MSB).

CHILE, Región de Coquimbo, Prov. Elqui, cuesta del Almendro, $21 \mathrm{~km}$ al sur de Vicuña, antes de Condoriaco, 1350 m, 23-IX-1957, R. Wagenknecht 5786 (G); Región de Coquimbo, laguna del Toro, 3450 m, 22-I-1966, C. Jiles 4855a (M); Prov. Limarí, Serón, a pleno campo, $1800 \mathrm{~m}$, 24-XI-1957, C. Jiles 3315 (CONC); La Condesa, 1400 m, 111952, C. Jiles 2346 (CONC); cordillera de Ovalle, El Chape, 3043'S, 70³8'W, 2600 m, 16-I-1949, C. Jiles 1198 (CONC); cordillera del río Gordito, 30-I-1954, C. Jiles 2520 (CONC); Combarbalá, Potrero Grande, 2600 m, 22-I-1966, C. Jiles 4835 (CONC); Prov. Choapa, near Río Ojotas, Northeast of La Vega Redonda, Andes back of Cuncumén, 3000 m, 25-II1939, J.L. Morrison \& R. Wagenknecht 17419 (GH, K); Prov. 
Indefinida, In Andibus prov. Coquimbo, H. Volckmann s.n. (SGO 42210, 54417); Región de Valparaíso, Prov. San Felipe, laguna above Junta de Piuquenes, río Sobrante, 3480 m, 12II-1939, J.L. Morrison 17282 (F, G, GH, K, M, S); cordillera de Los Patos, I-1884, Álamos s.n. (SGO 42214, 54416); Prov. Los Andes, valle de Arpa, 32 ${ }^{\circ} 39^{\prime} \mathrm{S}, 70^{\circ} 29^{\prime} \mathrm{W}, 2233 \mathrm{~m}$, 5-I-2009, M.F. Gardner \& S.G. Knees 8487 (E); Portillo, laguna del Inca, 3100 m, 16-I-1964, C. Marticorena \& O. Matthei 572 (CONC); Portillo, 3000 m, 29-XII-1946, E. Wall s.n. (S); Portillo, 3100 m, 28-VIII-1946, E. Wall s.n. (A); Región Metropolitana, Prov. Chacabuco, cerro El Roble Alto, laguna Chicauma, $1970 \mathrm{~m}$, 21-I-1939, J.L. Morrison \& R. Wagenknecht 17118 (G, GH, K, M, S); comuna de Lampa: altos de Lipangue, $33^{\circ} 17^{\prime} \mathrm{S}$, 7058'W, 1932 m, 13-I-2017, N. García, B. Hernández \& I. Quinteros 4632 (EIF); Prov. Cordillera, cordillera de Las Arañas, I-1860, C.L. Landbeck s.n. (SGO 42212, 54418); Tal La Paloma (Colorado -Maipo Tal), cordillera de Santiago, 2500 m, I-1939, C. Grandjot \& G. Grandjot 3390 (GH); cordillera de Santiago, 2-1854, P. Germain s.n. (SGO 54416, W 54416); Prov. Santiago, Cordillera du Chili, 1876, R.A. Philippi [Distr.] s.n. (G); Prov. Santiago, [Philippi?] s.n. (FI); Región de Maule, Prov. Curicó, Curicó, Los Queñes, 9-I-1939, E. Barros 6308 (GH); Curicó, Los Queñes, 19-II-1930, E. Barros 6325 (GH); camino de laguna de Teno a paso Vergara, km 7, $2250 \mathrm{~m}$, 10-III-1967, O. Matthei \& C. Marticorena 975 (CONC); Curicó, cordillera Potrero Grande, 31-I-1928, E. Barros 6332 (GH); volcán Peteroa, 2500 m, I-1925, E. Werdermann 587 (B, BM, CONC, E, F, G, GH, K, NY, S, U); Parque Nacional Siete Tazas, sector Parque Inglés, $35^{\circ} 28^{\prime} \mathrm{S}, 70^{\circ} 59^{\prime} \mathrm{W}, 1070$ m, 23-I-2003, M. Gardner, P. Hechenleitner, C. Martínez \& P.I. Thomas DCI77 (CONC, E); Curicó, Cordillera, II-1920, E. Barros 6327 (GH); Prov. Talca, Vilches, 8-I-1979, O. Zöllner 10221 (CONC); central Los Cipreses, a orillas del río, 3547'S, 7048'W, 900 m, 13-IV-2000, V. Finot \& P.López 2130 (CONC); valle de Maule, 3553'S, 70³9' W, $1330 \mathrm{~m}$, 5-II-1998, P. Baxter, P. Brownless, M. Bustos, M. Gardner, K. Matthews, H.S. Maxwell \& D. Rae 52 (E); río Maule, en la orilla, $35^{\circ} 55^{\prime} \mathrm{S}, 70^{\circ} 36^{\prime} \mathrm{W}, 1400 \mathrm{~m}, 21-\mathrm{I}-2005$, F. Luebert \& S. Teillier 2322 (CONC); cuesta Los Cóndores, camino a la Laguna del Maule, 3557'S, 70³4' W, 1880 m, 22-I-2005, F. Luebert \& S. Teillier 2241 (CONC); laguna del Maule, $36^{\circ} 0^{\prime} \mathrm{S}$, 70³0'W, 2190 m, 19-I-1961, F. Schlegel 3492 (CONC); western slopes of laguna del Maule, 36 $6^{\circ} 1^{\prime} \mathrm{S}, 70^{\circ} 33^{\prime} \mathrm{W}, 2180$ m, 6-II-1998, P. Baxter, P. Brownless, M. Bustos, M. Gardner, K. Matthews, H.S. Maxwell \& D. Rae 132 (E); entre tranque del Maule y la bocatoma del canal, 14-II-1963, M. Ricardi, C. Marticorena \& O. Matthei 1014 (CONC); upper Maule valley, 3658'S, 70³3'W, 2011 m, 22-II-2001, M. Gardner, C. Morter \& G. Ovstebo 27 (E); Talca, región andina, 28-I1922, R. Silva s.n. (CONC 121908); lecho del río Maule, IV-
1892, K. Reiche s.n. (SGO 61712); Región de Ñuble, Prov. Punilla, Los Moscos, Cordillera de Chillán, 2100 m, I-1937, C. Grandjot s.n. (GH); San Carlos (El Roble), 3-II-1921, E. Barros 6339 (GH); Ñuble, El Roble, 3-II-1929, E. Barros 6326 (GH); Prov. Diguillín, Recinto, 1500 m, 2-1950, V. Barros s.n. (CONC 124332); camino a termas de Chillán, Shangri-Lá,

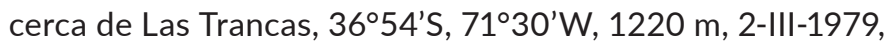
R. Rodríguez 1157 (CONC); nevados de Chillán, 16-I-1981, J. Grau 2750 (BM, M); termas de Chillán, II-1933, F. Jaffuel 2858 (CONC, GH); nevados de Chillán, Ansteig zum Refugio Shangri-La, 16-III-1981, J. Grau 3102 (M); termas de Chillán, 2-1937, F. Jaffuel 3789 (GH); termas de Chillán, 7-III-1947, A. Pfister s.n. (CONC 7554); Las Trancas, camino a termas de Chillán, 1200 m, 8-XII-1945, F. Behn s.n. (CONC 6485, 22285); baños de Chillán, 26-II-1862, [R.A. Philippi] s.n. (GH, SGO 42250); baños de Chillán, I-1878, [F. Philippi] s.n. (SGO 54416); Los Morros, Chillán, 1864, M.A. de Solis s.n. (SGO 54420); Prov. Indefinida, cordillera de Chillán, 1855, P. Germain s.n. (BM, F 639892, G, K, P, SGO 42209, 42213, 54416, W); Región de Biobío, Prov. Arauco, Laraquete, 15XII-1950, M. Ricardi s.n. (CONC 10465); Prov. Biobío, camino entre el longitudinal y Pangal del Laja, cerca de El Guape, 3711'S, 72¹9'W, $150 \mathrm{~m}, 29-\mathrm{XI}-1976$, C. Marticorena \& R. Rodríguez 8412 (CONC); cordillera de Polcura, $1000 \mathrm{~m}$, 26-II-1974, M. Ledezma 780 (CONC); laguna del Laja, 2-II1968, O. Zöllner 2582 (CONC); a orillas de la laguna del Laja, 22-I-1969, M. Ricardi \& C. Marticorena 5374/1895 (CONC); Parque Nacional Laguna del Laja, al pie de la Sierra Velluda, $37^{\circ} 26^{\prime} \mathrm{S}, 7^{\circ} 24^{\prime} \mathrm{W}, 1380 \mathrm{~m}, 24-\mathrm{I}-2001$, M. Baeza, M.J. Parra \& C. Torres 3267 (CONC); Trapa-Trapa,

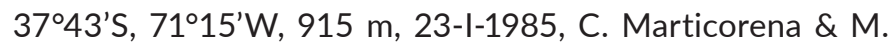
Quezada 9601 (CONC); camino de la reserva Ralco a Ralco,

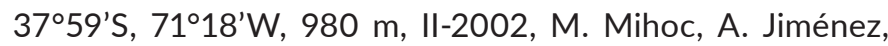
S. González y E. Badano 5062 (CONC); Prov. Indefinida, La Cueva, I-1887, C. Rahmer s.n. (SGO 42211, 54419); Región de Araucanía, Prov. Malleco, Piedra Marcada, III-1875, s.col. s.n. (SGO 42249); Lonquimay, II-1955, G. Montero 4825 (CONC); Lonquimay, 950 m, 27-XII-1968, M. Ricardi \& C. Marticorena 5653/1814 (CONC); camino de Termas de Manzanares a Lonquimay, km 29, 990 m, 9-II-1960, M. Ricardi \& C. Marticorena 5036/1420 (CONC); cordillera de Lonquimay, 1000 m, 13-II-1921, A. Hollermayer 437 (CONC, $\mathrm{GH}, \mathrm{S}, \mathrm{W}$ ); camino de Lonquimay a Galletué, a $32 \mathrm{~km}$ de La Fusta, 1200 m, 12-II-1960, M. Ricardi \& C. Marticorena 5132/1516 (CONC); Prov. Cautín, Galletué, 23-II-1976, P. Weisser 1538 (CONC); Parque Nacional Galletué, cerca del estero El Porfiado, $38^{\circ} 38^{\prime} \mathrm{S}, 71^{\circ} 25^{\prime} \mathrm{W}, 1250 \mathrm{~m}, 10-\mathrm{I}-1977$, C. Marticorena, M. Quezada \& R. Rodríguez 1449 (CONC); Parque Nacional Conguillío, playa de laguna Curacautín, 12II-1984, M. Muñoz 1875 (SGO); lago Conguillío, 16-I-1973, 
G. Montero 8914 (CONC); paso Pino Hachado, 1800-2000 m, 27-XII-1968, H. Merxmüller 24971 (M); Entre laguna Quililo y Melipeuco, a orillas del rio Quetralelfú, $38^{\circ} 46^{\prime}$ S, 71³8'W, 850 m, 11-I-1977, C. Marticorena, M. Quezada \& R. Rodríguez 1473 (CONC); laguna Icalma, en la arena cerca de la playa, 15-I-1947, A. Pfister s.n. (CONC 7378); Región de Aysén, Prov. Aysén, International highway East of Puerto Aysén, I-III-1934, A. Pirión 3381 (GH).

Comentarios: Heliotropium paronychioides está relacionada con H. geissei. Véase di Fulvio \& Ariza Espinar (2000), y comentarios bajo esta última especie.

En el protólogo se indican dos ejemplares: Bridges s.n. y Cuming 1255. El primero corresponde al lectotipo. EI segundo es en realidad una colecta de Bridges distribuida por Cuming (Johnston 1928b). En efecto, el número de colecta 1255 aparece bajo Heliotropium en las listas de plantas de Bridges consultadas en el archivo del Museo de Historia Natural de Londres.

Heliotropium patagonicum (Speg.) I.M. Johnst., Contr. Gray Herb. 81: 8. 1928. Valentina patagonica Speg., Anales Soc. Ci. Argent. 53: 78. 1902. Valentiniella patagonica (Speg.) Speg., Anales Mus. Nac. Buenos Aires ser. 3, 2: 9. 1903. TIPO: ARGENTINA, Costa del río Chubut, XI-1897, [J. Valentín] s.n. (lectotipo, designado por Luebert (2017: 793), LP 006698 [fototipo!]). Sintipos remanentes: ARGENTINA, S. Julian R. Deseado, 1899, C. Ameghino s.n. (LP [fototipo!]); Karr-aik (Lago Argentino), III-1898 C. Ameghino s.n. (LP [fototipo!]).

Iconografía: Gangui (1955: 501, fig. 2A-C), Correa (1999: 135, fig. 94).

Referencias: Macloskie et al. (1914: 214), Johnston (1928a: 8), Gangui (1955: 500), Correa (1999: 134), di Fulvio \& Ariza Espinar (2016: 776), Luebert (2017: 793).

Hierba perenne, postrada, de hasta $30 \mathrm{~cm}$ de diámetro y 10 $\mathrm{cm}$ de alto, glabra. Hojas opuestas o subopuestas, solitarias, imbricadas en grupos de hojas grandes y pequeñas, sésiles - subsésiles, glabras; lámina suborbicular, concolora, sin nervios marcados, carnosa, 3-10(-15) x 3-12 mm, margen entero, base y ápice redondeados. Inflorescencias terminales o axilares, dicotómicamente ramificadas hasta en 2 niveles, de 1-4 cm de largo. Flores subsésiles, 4,5-6 mm de largo. Cáliz persistente, dividido casi hasta la base; sépalos aovados, glabros, ca. 2-3 mm de largo, ca. $1 \mathrm{~mm}$ de ancho en la base, ápice obtuso o agudo. Corola hipocrateriforme, blanca con el centro amarillo tornándose lila o violeta en la madurez, 4,5$7 \mathrm{~mm}$ de largo, ca. $4 \mathrm{~mm}$ de diámetro; lóbulos redondeados o agudos, ca. 0,5 mm de diámetro; tubo glabro en ambas caras, amarillo por fuera. Estambres inclusos; filamentos adnados a los pétalos; anteras libres, aovadas, $c a$. 1-1,5 mm de largo, base cordada, localizada aproximadamente sobre la porción receptiva de la columna estigmática a cerca de 1/2$1 / 3$ de la base del tubo; ápice apiculado, papiloso. Ovario glabro, ca. $1 \mathrm{~mm}$ de alto, ca. $1 \mathrm{~mm}$ de diámetro, con disco nectarífero desarrollado en la base. Estilo más corto que la columna estigmática, ca. 0,2-0,3 mm de largo. Columna estigmática cónica, ca. 0,4 -0,5 mm de largo, ca. 0,5 mm de ancho en la base, glabra. Frutos secos, glabros, ca. 2-3 x $4 \mathrm{~mm}$, separándose en 4 nueces uniseminadas. Nueces sin cavidades vacías, superficie dorsal lisa o ligeramente reticulada.

Distribución: Patagonia austral, principalmente en Argentina. En Chile sólo ha sido reportada para Tierra del Fuego en una localidad por Pisano (1976), confirmada con recolectas posteriores (Fig. 6) en ambiente de playa arenosa en la orilla sur del estrecho de Magallanes (Fig. 7).

Especímenes examinados: ARGENTINA, Prov. Chubut, Depto. Languiñeo, road Esquel-Tecka-Rawson, road km 417,

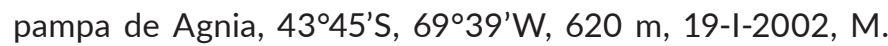
Weigend, H. Förther, N. Dostert \& K. Weigend 6940 (BM, MSB, W); Depto. Tehuelches, near estancia Providencia, 10 $\mathrm{km} \mathrm{W}$ of laguna del Toro, $44^{\circ} 23^{\prime} \mathrm{S}, 70^{\circ} 35^{\prime} \mathrm{W}, 624 \mathrm{~m}, 28-\mathrm{I}-$ 2002, M. Weigend, H. Förther, N. Dostert \& K. Weigend 7012 (BM, F, M, MSB, W); Prov. Santa Cruz, Depto. Rio Chico, RN $40 \mathrm{~N}$ from Calafate towards Perito Moreno, before bridge over Río Chico, near Estancia La Angostura, 48 $46^{\prime} \mathrm{S}, 70^{\circ} 45^{\prime} \mathrm{W}, 372 \mathrm{~m}, 26-\mathrm{I}-2002$, M. Weigend, H. Förther, N. Dostert \& K. Weigend 6993 (BONN, MSB); Depto. Magallanes, San Julián, 27-XII-1935, A.L. Blake 275 (K); San Julián, 213 m, 6-XII-1945, A.L. Blake 349 (K).

CHILE, Región de Magallanes, Prov. Tierra del Fuego, half way between punta Remo and punta Baxa, 19-I-1977, J.C. Emerick s.n. (HIP 4187); Entre punta Remo y bahía Azul, $52.710367^{\circ} \mathrm{S}, 69.659619^{\circ} \mathrm{W}, 0 \mathrm{~m}, 4-\mathrm{I}-2016$, F. Luebert \& E. Daniłowicz-Luebert 3249 (BONN, EIF).

Comentarios: Johnston (1928a) incluyó esta especie en la sección Coeloma, pero estudios filogenéticos recientes muestran su afinidad con Heliotropium curassavicum (Hilger \& Diane 2003, Luebert et al. 2011), de manera que aquí se incluye dentro de la sección Platygyne. Moore (1983) no cita a H. patagonicum para Tierra del Fuego a pesar de haber sido reportada con anterioridad (Pisano 1976). Tampoco lo hacen Rodríguez et al. (2018), aunque la referencia antes mencionada estaba aparentemente recogida en Marticorena 
\& Quezada (1985) y Zuloaga et al. (2018), este último "sin mencionar material de referencia". Se diferencia de $H$. curassavicum por sus hojas suborbiculares versus las hojas lineal- espatuladas o espatuladas de H. curassavicum.

\section{ESPECIES ERRÓNEAMENTE CITADAS O DUDOSAS PARA CHILE}

Euploca procumbens (Mill.) Diane \& Hilger, Bot. Jahrb. Syst. 125(1): 48. 2003.

Heliotropium procumbens Mill., Gard. Dict., ed. 8. n. 10. 1768. TIPO: [Colombia, Bolívar], America australis: Carthagena, Houston (holotipo BM!).

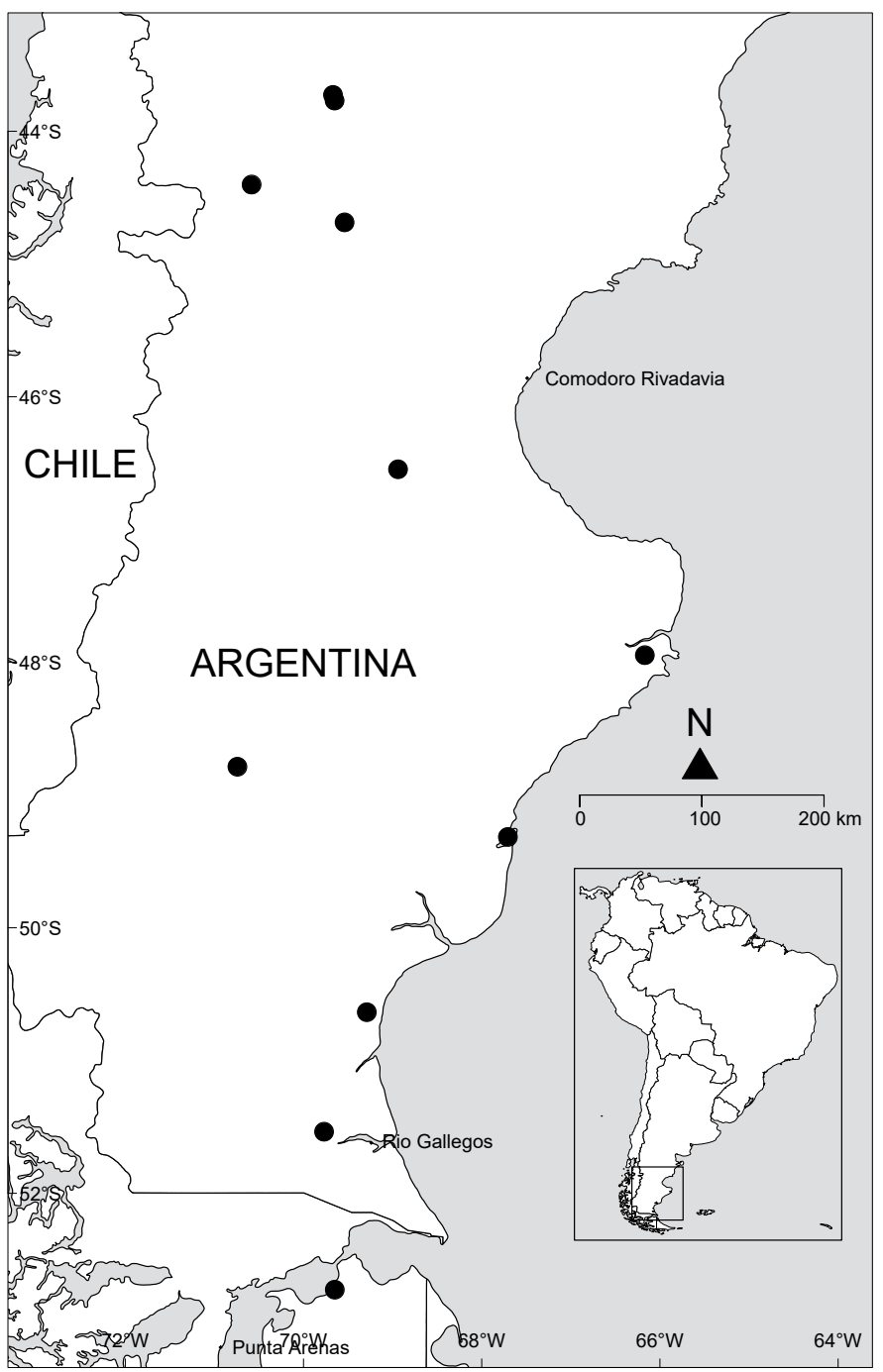

Figura 6. Mapa de distribución de Heliotropium patagonicum. Además de los ejemplares examinados se utilizó información de localidades de Correa (1999) y di Fulvio \& Ariza Espinar (2016). / Distribution map of Heliotropium patagonicum. Apart from the examined specimens, locality information from Correa (1999) and di Fulvio \& Ariza Espinar (2016) was employed.
Esta especie fue mencionada para Chile por Meyen (1834: 436) y Johnston (1928a: 54), sobre la base de un ejemplar, que constituye el tipo de Heliotropium simplex Meyen, que Johnston (1928a) coloca bajo la sinonimia de Euploca procumbens (sub Heliotropium procumbens). Esta información es recogida por Marticorena \& Quezada (1985). Sin embargo, el nuevo análisis del material tipo reportado por Johnston (1937: 17-18) concluye que $H$. simplex es en realidad un sinónimo de $H$. angiospermum y que en la etiqueta de dicho material se indica Lima como localidad de recolección. Sería interesante poder confirmar la afirmación de Johnston (1937), pero ello no es posible, ya que el material tipo de $H$. simplex estaba depositado en Berlín y fue destruido durante la II Guerra Mundial. Tampoco existe una foto entre los negativos del Field Museum de Chicago. Lo anterior, sumado a la ausencia de otras recolecciones de la especie en el país, descarta a Euploca procumbens para Chile. La especie no es mencionada para Chile por Zuloaga et al. (2008) ni por Rodríguez et al. (2018).

Comentarios: Förther (1998: 214) cita dos sintipos, con una lectotipificación de Howard (1989: 204), pero en la descripción de Miller (1768) sólo se ve nombrada una planta, que es la mencionada aquí.

Heliotropium angiospermum Murray, Prodr. Stirp. Gott. 217-219. 1770. TIPO: No designado. El tipo corresponde a una planta cultivada en Göttingen a partir de semillas enviadas por Oeder en 1768. Revisé material en GOET en dos ocasiones y no encontré ejemplares de herbario que pudiesen corresponder al tipo. Es posible que se requiera aquí una tipificación, aunque la aplicación del nombre es muy clara.

Se trata de una especie que se distribuye naturalmente desde el sur de Estados Unidos hasta el centro-sur de Perú (Macbride 1960; Johnston 1964; Melo \& Semir 2008), y que, de acuerdo con Arroyo (2000), se ha naturalizado en Chile. La primera cita de esta especie para Chile viene de Meyen (1834: 436), quien menciona Heliotropium synzystachyum Ruiz \& Pav. (=Heliotropium angiospermum, véase Luebert \& Hilger 2014) para la zona de Arica. Este material es posteriormente citado por Johnston (1928a: 11), Macbride (1960: 558) y Zuloaga et al. (2008: 1645), quienes se basan en él para registrar la especie en Chile, información que también es recogida en Marticorena \& Quezada (1985), Rodríguez et al. (2018) y Pauchard et al. (2020). Desafortunadamente, el material de Meyen estaba depositado en Berlín y fue destruido durante la II Guerra Mundial. La revisión crítica de numerosos ejemplares de 

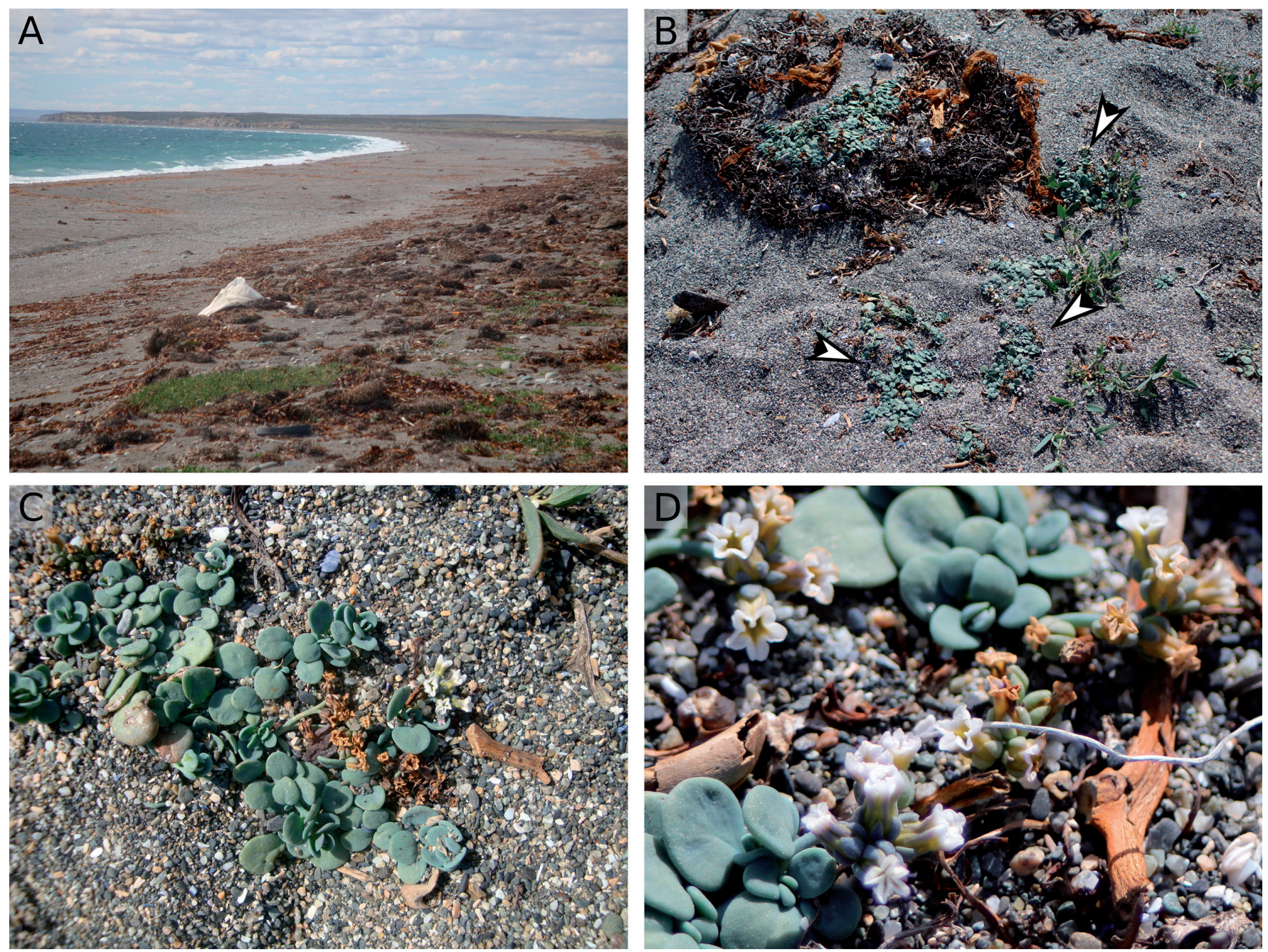

Figura 7. Heliotropium patagonicum en Chile. A, Hábitat natural; B; Aspecto de la planta (indicada con flechas); C, Aspecto de la planta e inflorescencia; D, Aspecto de hojas y flores. Fotos tomadas en la orilla sur del estrecho de Magallanes, entre punta Remo y bahía Azul, enero de 2016. / Heliotropium patagonicum in Chile. A, Natural habitat; B; Apect of plant (shown with arrows); C, Aspect of leaves and inflorescences; D, Aspect of leaves and flowers. Pictures taken at the southern edge of the Strait of Magellan between punta Remo and bahía Azul, January 2016.

herbario por parte del autor (más de 1000) no ha dado con ninguno que pueda ser inequívocamente referido para Chile. Tampoco se conocen recolectas o avistamientos recientes de la especie en el país. El autor no ha encontrado materiales peruanos de la especie recolectados al sur del departamento de Arequipa y el material citado para Tacna por Macbride (1960) es el tipo de Heliotropium simplex, ya discutido arriba bajo Euploca procumbens. Existe un ejemplar de T. Haenke de 1790 (Haenke 2085, NY) en cuya etiqueta se lee "Chile". Si bien Haenke visitó y recolectó en Chile en 1790, también lo hizo en Perú y Ecuador (Gicklhorn 1966), donde la especie ha sido ampliamente documentada. Hay también un ejemplar atribuido a D'Urville (P03877075) etiquetada a posteriori como proveniente de Chile, pero sin mayor indicación.
Ninguno de estos materiales es posterior a la década de 1830. La especie es también citada para Chile (GBIF Secretariat 2019) por referencia incorrecta a Heliotropium rugosum Mart. \& Gal., sinónimo de H. angiospermum y homónimo anterior de Heliotropium rugosum Phil. (nom illegit.), este último sinónimo de $\mathrm{H}$. taltalense (Phil.) I.M. Johnst., especie endémica de Chile (Johnston 1928a; Luebert 2013). Ya que Heliotropium angiospermum se comporta como ruderal en toda su área de distribución, no es posible descartar que la especie haya estado presente en Chile en el pasado, pero que sus poblaciones no se hayan estabilizado. Debido a la ausencia de recolecciones modernas de la especie en Chile y las dudas sobre los materiales disponibles, considero que su presencia en el país es dudosa y debe ser descartada hasta que nuevos materiales se hagan disponibles. 
Catálogo de las especies chilenas de Heliotropium Heliotropium L.

H. sect. Cochranea (Miers) Kuntze

1. H. chenopodiaceum (A. DC.) Clos

2. H. eremogenum I.M. Johnst.

3. H. filifolium (Miers) I.M. Johnst.

4. H. floridum (A. DC.) Clos

5. H. glutinosum Phil.

6. H. inconspicuum Reiche

7. H. jaffuelii I.M. Johnst.

8. H. krauseanum Fedde

9. H. linariifolium Phil.

10. H. longistylum Phil.

11. H. megalanthum I.M. Johnst.

12. H. myosotifolium (A. DC.) Reiche

13. H. philippianum I.M. Johnst.

14. H. pycnophyllum Phil.

15. H. sinuatum (Miers) I.M. Johnst.

16. H. stenophyllum Hook. \& Arn.

17. H. taltalense (Phil.) I.M. Johnst.
H. sect. Heliothamnus I.M. Johnst.

18. H. corymbosum var. grisellum (I.M. Johnst.) Luebert

H. sect. Heliotrophytum G. Don

19. H. amplexicaule Vahl

H. sect. Hypsogenia I.M. Johnst.

20. H. microstachyum Ruiz \& Pav.

H. sect. Plagiomeris I.M. Johnst.

21. H. geissei F. Phil.

22. H. paronychioides A. DC.

H. sect. Platygyne Benth.

23. H. curassavicum L.

24. H. patagonicum (Speg.) I.M. Johnst.

Clave para determinar las especies Chilenas de Heliotropium

1 Plantas leñosas, arbustos o subarbustos

- Plantas herbáceas, perennes o anuales, a veces con la base del tallo leñosa

2 Hojas con limbo amplio, de más de $2 \mathrm{~cm}$ de ancho. El fruto se divide en 4 nueces uniseminadas H. corymbosum var. grisellum

- Hojas pequeñas, generalmente menos de $1 \mathrm{~cm}$ de ancho, muy raramente hasta $1,5 \mathrm{~cm}$ de ancho. Fruto se divide en 2 nueces

biseminadas o permanece sin dividirse (sect. Cochranea)

3

3 Hojas enroscadas en los márgenes, estos muy aproximados, formando un tubo. Estilo y columna estigmática cortamente híspidos. Cáliz permanece adherido al fruto durante la dispersión. Fruto tetraseminado que no se divide . H. pycnophyllum

- Hojas terete o con margen revoluto, nunca formando un tubo. Estilo y columna estigmática glabros. El cáliz permanece adherido a la inflorescencia durante la dispersión. El fruto se divide en dos nueces biseminadas

4 Hojas de sección transversal redonda, columna estigmática sésil o subsésil .................................................................................... 5

- Hojas de sección transversal plana con el margen revoluto. Columna estigmática y estilo claramente distinguibles 6

5 Limbo de la corola de más de $4 \mathrm{~mm}$ de ancho. Plantas de la Región de Atacama

H. filifolium

- Limbo de la corola de menos de $4 \mathrm{~mm}$ de ancho. Plantas endémicas del área de Tocopilla H. jaffuelii

6(4) Hojas con margen sinuado, rugosas en la cara adaxial 7

- Hojas con margen entero, no rugosas en la cara adaxial

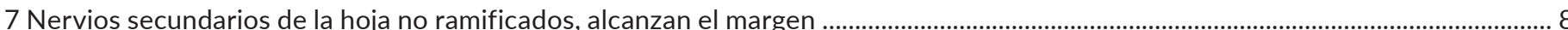

- Nervios secundarios de la hoja ramificados

8 Glándulas sobre las hojas evidentes a simple vista. Estilo más corto que la columna estigmática

- Glándulas sobre las hojas no evidentes a simple vista. Estilo tan o más largo que la columna estigmática

H. taltalense

estigmática. Planta de la costa de la provincia de Antofagasta

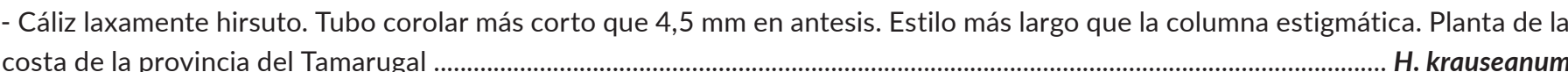

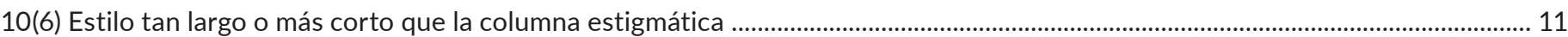

- Estilo definitivamente más largo que la columna estigmática ............................................................................................................. 16

11 Tallos sin pubescencia estrigosa evidente a simple vista en las partes vegetativas de la planta ...................................................... 12 
- Tallos con pubescencia estrigosa evidente a simple vista en las partes vegetativas de la planta

12 Las hojas mayores de la planta más largas que $15 \mathrm{~mm}$

H. stenophyllum

- Las hojas mayores de la planta más cortas que $15 \mathrm{~mm}$

13 Hojas lineal-oblongas con dos bandas blancas conspicuas en la cara abaxial. Estilo tan largo como la columna estigmática

H. inconspicuum

- Hojas lineal-lanceoladas sin bandas blancas en la cara abaxial. Estilo 3 o más veces más corto que la columna estigmática

14(11) Hojas pubescentes sólo en el margen

H. chenopodiaceum

- Hojas pubescentes en toda la lámina

H. megalanthum que $5 \mathrm{~mm}$ de ancho

- Plantas no glutinosas. Lóbulos del cáliz libres. Limbo de la corola de 5-7 mm de ancho

H. chenopodiaceum

16(10) Hojas glabras

H. myosotifolium

- Hojas pubescentes

H. longistylum

17 Hojas más cortas que $6,5 \mathrm{~cm}$. Plantas del área de Antofagasta (quebrada La Chimba-morro Moreno) o de más al norte

H. eremogenum

- Hojas generalmente más largas que 6,5 cm. Plantas del sur de Antofagasta

18 Arbustos decumbentes. Corola naranja

- Arbustos erectos. Corola blanca

19 Arbustos generalmente más bajos que 0,6 m. Plantas del área de Chañaral o de más al sur

- Arbustos más altos que 0,6 m. Plantas de más al norte que Taltal

H. floridum

20(1) Hierbas anuales. Hojas pecioladas (sect. Plagiomeris)

H. philippianum

- Hierbas perennes. Hojas sésiles o subsésiles

21

21 Hojas oblongas, más largas que anchas, con sólo un nervio medio notorio en la cara abaxial. Nueces glabras o laxamente pubescentes, con pelos simples H. paronychioides

- Hojas orbiculares o suborbiculares, tan largas como anchas, con los nervios medio y secundarios notorios en la cara abaxial.

Nueces cubiertas de papilas digitiformes

H. geissei

22(20) Hojas glabras. El fruto se divide en 4 nueces uniseminadas (sect. Platygyne) .............................................................................. 23

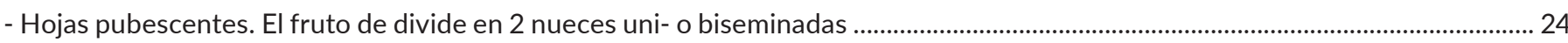

23 Hojas lineales o lineal-espatuladas

H. curassavicum

- Hojas orbiculares o suborbiculares

H. patagonicum

24(22) Plantas rastreras, con rizomas, de $5-30 \mathrm{~cm}$ de alto. Hojas con pubescencia simple, adpresa, sin pubescencia glandulosa. Corola de hasta $2,5 \mathrm{~mm}$ de largo H. microstachyum

- Plantas erectas, con raíz fibrosa, de $20-60$ cm de alto. Hojas con pubescencia glandulosa y simple. Corola de 4-8 mm de largo .......

H. amplexicaule

\section{AGRADECIMIENTOS}

A los curadores de los herbarios consultados por las facilidades otorgadas para la consulta de materiales. A Galina Karabascheva por preparar la ilustración de Heliotropium corymbosum var. grisellum. A Stephen Harris y Serena Marner (OXF) por facilitar la imagen del tipótipo de Heliotropium curassavicum. A Juan Marcos Henríquez (HIP) por el envío de fotografías de Heliotropium patagonicum. A Michael O. Dillon, Emil di Fulvio, Hartmut. H. Hilger, Mélica Muñoz-Schick y Jun Wen por su ayuda. Al Servicio Alemán de Intercambio
Académico (DAAD) y Smithsonian Institution por el apoyo financiero. A Irmtraut Vogt-Schmickler del Instituto de Geografía, Universidad de Bonn por las facilidades para consultar diario de C. Troll. Esta investigación recibió apoyo del proyecto SYNTHESYS https://www.synthesys.info/ que es financiado por la European Community Research Infrastructure Action bajo los programas FP6 "Structuring the European Research Area" (grant GB-TAF-4514) y FP7 "Capacities" (grants ES-TAF-136, AC-TAF-2001, FR-TAF 1977, SE-TAF-4797, GB-TAF-4761). A tres revisores anónimos por sus valiosas sugerencias. 


\section{REFERENCIAS}

Arroyo, M.T.K., Marticorena, C. 1985. Additions to the flora of Chile: New records from the Altiplano. Gayana Botánica 42(3-4): 3-7.

Arroyo, M.T.K., Marticorena, C., Matthei, O., Cavieres, L.A. 2000. Plant invasions in Chile: Present patterns and future predictions. En: Mooney, H.A., Hobbs, R.J. (Eds.) Invasive species in a changing World, pp. 385-421. Island Press, New York.

Autrey, J.C., Bosser, J., Ferguson, I.K. 2005. Flore des Mascareignes: La Réunion, Maurice, Rodrigues. 121 Apocynacées à 126 Boraginacées. IRD Editions, Paris. $162 \mathrm{pp}$

Becker, R.A., Wilks, A.R., Brownrigg, R. 2016. mapdata: Extra Map Databases. R package version 2.3.0. URL: https:// CRAN.R-project.org/package $=$ mapdata

Becker, R.A., Wilks, A.R., Brownrigg, R., Minka, T.P., Deckmyn, A. 2017. maps: Draw Geographical Maps. $R$ package version 3.3.0. URL: https://CRAN.R-project.org/package $=$ maps

Bertero, C.G. 1829. Continuación de catálogo de plantas examinadas en Chile por el Dr. Bertero. Mercurio Chileno 14: 639-651.

Brako, L., Zarucchi, J.L. 1993. Catalogue of the flowering plants and gymnosperms of Peru. Monographs in Systematic Botany from the Missouri Botanical Garden 45: 1-1286.

de Candolle, A.L.P.P. 1845. Prodromus systematis naturalis regni vegetabilis. Vol. 9. Fortin, Masson et Sociorum, Paris. 573 pp.

Correa, M.N. 1999. Boraginaceae. En: Correa, M.N. (Ed.) Flora Patagónica, Parte VI, pp. 116-146, Colección Científica del INTA, Buenos Aires.

Correll, D.S., Correll, H.B. 1982. Boraginaceae. Flora of the Bahama Archipelago, pp. 1193-1214, J. Cramer, Vaduz.

Craven, L.A. 1996. A taxonomic revision of Heliotropium (Boraginaceae) in Australia. Australian Systematic Botany 9(4): 521-657.

Dawson, G. 1965. Boraginaceae. En: Cabrera, A.L. (Ed.) Flora de la Provincia de Buenos Aires, pp. 100-121, Colección Científica del INTA, Buenos Aires.

Diane, N., Förther, H., Hilger, H.H. 2002. A systematic analysis of Heliotropium, Tournefortia, and allied taxa of the Heliotropiaceae (Boraginales) based on ITS1 sequences and morphological data. American Journal of Botany 89(2): 287-295.

Diane, N., Hilger, H.H., Förther, H., Weigend, M., Luebert, F. 2016. Heliotropiaceae. En: Kadereit, J.W., Bittrich, V. (Eds.) The families and genera of vascular plants, Vol. 14, pp. 203-211, Springer International Publishing, Cham.
Ewan, J. 1942. A review of the North American weedy Heliotropes. Bulletin of the Southern California Academy of Sciences 41: 51-57.

Förther, H. 1998. Die infragenerische Gliederung der Gattung Heliotropium L. und ihre Stellung innerhalb der Subfam. Heliotropioideae (Schrad.) Arn. (Boraginaceae). Sendtnera 5: 35-241.

Frohlich, M.W. 1981. Heliotropium. En: Gómez-Pompa, A. (Ed.) Flora de Veracruz, Vol. 18, pp. 70-104, Instituto Nacional de Investigaciones sobre Recursos Bióticos, Xalapa.

di Fulvio, T.E., Ariza-Espinar, L. 2000. Heliotropium geissei (Boraginaceae) en Argentina. Kurtziana 28(2): 275-278.

di Fulvio, T.E., Ariza Espinar, L. 2016. Las especies argentinas de Heliotropium (Boraginaceae). Boletín de la Sociedad Argentina de Botánica 51(4): 745-787.

Gangui, N. 1955. Las especies silvestres de Heliotropium de la República Argentina. Revista de la Facultad de Ciencias Exactas, Físicas y Naturales 17: 481-560.

García, N. 2010. Caracterización de la flora vascular de Altos de Chicauma, Chile (33 ${ }^{\circ}$ S). Gayana Botánica 67(1): 65-112.

GBIF. 2019. Heliotropium angiospermum Murray in GBIF Backbone Taxonomy. Checklist dataset (accessed via GBIF.org). URL: https://doi.org/10.15468/39omei Accessed: May 2, 2020.

Gibson, D.N. 1970. Boraginaceae in Flora of Guatemala - part IX, numbers 1 and 2. Fieldiana, Botany 24(9/1-2): 111167.

Gicklhorn, R. 1966. Thaddäus Haenkes Reisen und Arbeiten in Südamerika. Franz Steiner Verlag, Weisbaden. 231 pp.

Guimarães, E.F., Barroso, G.M., Falcão-Ichaso, C.L., Rangel Bastos, A. 1971. Flora da Guanabara: Flacourtiaceae, Olacaceae, Boraginaceae. Rodriguésia 26(38): 142-246.

Hilger, H.H., Diane, N. 2003. A systematic analysis of Heliotropiaceae (Boraginales) based on trnL and ITS1 sequence data. Botanische Jahrbücher für Systematik, Pflanzengeschichte und Pflanzengeographie 125: 19-51.

Howard, R.A. 1989. Boraginaceae. Flora of the Lesser Antilles, Vol. 6, pp. 188-2011, Arnold Arboretum, Harvard University, Jamaica Plain, Massachusetts.

Ibáñez, S., Luebert, F., Gómez, M. 2011. Primer registro de Heliotropium amplexicaule (Heliotropiaceae) en Chile. Gayana Botánica 68(1): 89-92.

Jarvis, C. 2007. Order out of chaos. Linnaean plant names and their types. The Linnean Society of London and Natural History Museum, London. 1016 pp.

Johnston, I.M. 1928a. Studies in the Boraginaceae VII.1. The South American species of Heliotropium. Contributions from the Gray Herbarium of Harvard University 81: 3-73.

Johnston, I.M. 1928b. The botanical activities of Thomas Bridges. Contributions from the Gray Herbarium of 
Harvard University 81: 98-106.

Johnston, I.M. 1935. Studies in Boraginaceae X. The Boraginaceae of northeastern South America. Journal of the Arnold Arboretum 16: 1-64.

Johnston, I.M. 1936. Boraginaceae. En: Pulle, A.A. (Ed.) Flora of Suriname, Vol. 4(1), pp. 306-333. Koninklijke Vereeniging Koloniaal Instituut, Amsterdam.

Johnston, I.M. 1937. Studies in the Boraginaceae XII. 2. Novelties and critical notes. Journal of the Arnold Arboretum 18: 10-25.

Johnston, I.M. 1942. Boraginaceae. En: Kearney, T.H., Peebles, R.H. (Eds.) Flowering plants and ferns of Arizona, pp. 740-761. United States Department of Agriculture, Washington, D.C.

Johnston, I.M. 1949. Studies in the Boraginaceae XVIII. Boraginaceae of the southern West Indies. Journal of the Arnold Arboretum 30: 111-138.

Johnston, I.M. 1959. Some noteworthy American Borages. Wrightia 2: 13-22.

Johnston, I.M. 1964. Boraginaceae. En: Lundell, C.L. (Ed.) Flora of Texas, Vol. 1, pp. 123-221. Texas Research Foundation, Renner, Texas.

Juan, R., Talavera, S. 2012. Heliotropium. En: Castroviejo, S. (Ed.) Flora Ibérica, Vol. 11, pp. 527-532. Real Jardín Botánico, Madrid.

Liogier, E.E. 1957. Boraginaceae. En: Sauget, J.S., Liogier, E.E. (Eds.) Flora de Cuba, Vol. 4, pp. 252-278, P. Fernández, La Habana.

Liogier, H.A. 1994. Boraginaceae. La flora de la Española, Vol. 6, pp. 121-182. Editorial de la Universidad de Puerto Rico, San Juan.

Liogier, H.A. 1995. Boraginaceae. Descriptive flora of Puerto Rico and ajacent islands, Vol. 4, pp. 298-333. Editorial de la Universidad de Puerto Rico, San Juan.

Luebert, F. 2013. A revision of Heliotropium sect. Cochranea (Heliotropiaceae). Kew Bulletin 68(1): 1-54.

Luebert, F. 2017. Los géneros de Heliotropiaceae en Argentina. Boletín de la Sociedad Argentina de Botánica 52(4): 787796.

Luebert, F., Brokamp, G., Wen, J., Weigend, M., Hilger, H.H. 2011. Phylogenetic relationships and morphological diversity in Neotropical Heliotropium (Heliotropiaceae). Taxon 60(3): 663-680.

Luebert, F., Hilger, H.H. 2014. Typification of Heliotropium and Tournefortia (Heliotropiaceae) species described by Ruiz and Pavón. Anales del Jardín Botánico de Madrid 71(2): e012.

Luebert, F., Muñoz-Schick, M. 2014. Heliotropium geissei (Heliotropiaceae): nuevos registros, tipificación, posición sistemática y estado de conservación. Gayana Botánica
71(1): 30-36.

Luebert, F., Pliscoff, P. 2017. Sinopsis bioclimática y vegetacional de Chile. Ed. 2. Editorial Universitaria, Santiago. 384 pp.

Luebert, F., Weigend, M., Hilger, H.H. 2010. Epitypification of Heliotropium arborescens L. (Heliotropiaceae). Taxon 59(4): 1263-1266.

Luebert, F., Wen, J. 2008. Phylogenetic analysis and evolutionary diversification of Heliotropium sect. Cochranea (Heliotropiaceae) in the Atacama Desert. Systematic Botany 33(2): 390-402.

Macbride, J.F. 1960. Flora of Peru: Boraginaceae. Field Museum of Natural History, Botanical Series 13(5, 2): 539-609.

Macloskie, G., Dusén, P., Skottsberg, C. 1914. Revision of Flora Patagonia. Reports of the Princeton University Expeditions to Patagonia, Botany 8(Suppl.): 1-307.

Marticorena, C., Quezada, M. 1985. Catálogo de la flora vascular de Chile. Gayana Botánica 42(1-2): 1-157.

Martins, E.S. 1990. 116. Boraginaceae. En: Launert, E., Pope, G.V. (Eds.) Flora Zambesiaca, vol. 7, part 4, pp. 59-114. Flora Zambesiaca Managing Committee, London.

Melo, J.I.M., Semir, J. 2008. Taxonomia do gênero Heliotropium L. (Heliotropiaceae) no Brasil. Acta Botanica Brasilica 22: 754-770.

Meyen, F.J.F. 1834. Reise um die Erde. Vol. 1. Sander'sche Buchhandlung, Berlin.

Miller, J.S. 1988. A revised treatment of Boraginaceae for Panama. Annals of the Missouri Botanical Garden 75: 456-521.

Miller, J.S. 2001. Boraginaceae. En: Stevens, W.D., Ulloa Ulloa, C., Pool, A., Montiel, M. (Eds.) Flora de Nicaragua, Vol. 1, pp. 435-455. Missouri Botanical Garden, St. Louis.

Miller, J.S. 2012. Heliotropiaceae. En: Davidse G., Sousa Sánchez M., Knapp S., Chiang Cabrera F. (Eds.) Flora Mesoamericana, Vol. 4(2), pp. 310-317. Missouri Botanical Garden Press, St. Louis.

Miller, P. 1768. The gardeners dictionary. Ed. 8. Printed for the author, London.

Moore, D.M. 1983. Flora of Tierra del Fuego. Anthony Nelson and Missouri Botanical Garden, Oswestry and St. Louis. $396 \mathrm{pp}$.

Muñoz-Schick, M., Morales, V. 2013. Complemento y correcciones al "Catálogo de plantas vasculares del Cono Sur", para la flora de Chile. Boletín Museo Nacional de Historia Natural Chile 62: 167-201.

Munz, P., Keck, D. 1965. A California flora. University of California Press, Berkeley. 1681 pp.

Navas, L.E. 1979. Flora de la cuenca de Santiago de Chile. Vol. 3. Ediciones de la Universidad de Chile, Santiago. 509 pp.

Nowicke, J.W. 1969. Flora of Panama, part IX, family 167. Boraginaceae. Annals of the Missouri Botanical Garden 
56(1): 33-69.

Pauchard, A., Sanchez, P., Aldridge, D., Díaz, G.M., Volkart, N.S., Skewes, O., Wong, L.J., Pagad, S. 2020. Global register of introduced and invasive species - Chile. Version 2.6. Invasive Species Specialist Group ISSG. Checklist dataset (accessed via GBIF.org). URL: https://doi.org/10.15468/ n4ofia Accessed: May 2, 2020.

Pérez-Moreau, R.L. 1979. Boraginaceae. En: Burkart, A. (Ed.) Flora Ilustrada de Entre Ríos, Vol. 5, pp. 209-229, Instituto Nacional de Tecnología Agropecuaria, Buenos Aires.

Pérez-Moreau, R.L. 1994. Boraginaceae. En: Pérez-Moreau, R.L. (Ed.) Flora Chaqueña, Vol. 8, pp. 3-35, Instituto Nacional de Tecnología Agropecuaria, Buenos Aires.

Pérez-Moreau, R.L., Cabrera, A.L. 1983. Boraginaceae. En: Cabrera, A.L. (Ed.) Flora de la provincia de Jujuy, República Argentina, Vol. 8, pp. 247-291. Colección Científica del INTA, Buenos Aires.

Pérez-Moreau, R.L., Crespo, S., Luebert, F. 2017. Boraginaceae. En: Kiesling R. (Ed.) Flora de San Juan, Vol. 3A, pp. 49-72. Zeta Editores, Mendoza.

Philippi, F. 1881. Catalogus plantarum vascularium Chilensium. Imprenta Nacional, Santiago. 378 pp.

Philippi, R.A. 1895. Plantas nuevas chilenas que corresponden al tomo IV de la obra de Gay (continuación). Anales de la Universidad de Chile 90: 337-358.

Pinto, R., Luebert, F. 2009. Datos sobre la flora vascular del desierto costero de Arica y Tarapacá, Chile, y sus relaciones fitogeográficas con el sur de Perú. Gayana Botánica 66(1): 28-49.

Pisano, E. 1976. Adiciones a la flora vascular nativa de Tierra del Fuego. Anales del Instituto de la Patagonia 7: 155-177.

R Core Team. 2017. R: A Language and Environment for Statistical Computing. R Foundation for Statistical Computing, Vienna.
Reiche, K. 1907. Estudios críticos sobre la flora de Chile. Borrajináceas. Anales de la Universidad de Chile 121: 227-282.

Reiche, K. 1910. Boraginaceae. En: Reiche, K. (Ed.) Flora de Chile, Vol. 5, pp. 185-240. Imprenta Cervantes, Santiago.

Risopatrón, L. 1924. Diccionario jeográfico de Chile. Imprenta Universitaria, Santiago. 958 pp.

Rodríguez, G. 1993. El género Heliotropium L. (Boraginaceae) en Venezuela. Sinopsis. Acta Botanica Venezuelica 16(2-4): 83-91.

Rodríguez, R., Marticorena, C., Alarcón, D., Baeza, C.M., Cavieres, L.A., Finot, V.L., Fuentes, N., Kiessling, A., Mihoc, M., Pauchard, A., Ruiz, E., Sánchez, P., Marticorena, A. 2018. Catálogo de las plantas vasculares de Chile. Gayana Botánica 75(1): 1-430.

Ruhm, J., Böhnert, T., Weigend, M., Merklinger, F.F., Stoll, A., Quandt, D., Luebert, F. 2020. Plant life at the dry limit - spatial patterns of floristic diversity and composition around the hyperarid core of the Atacama Desert. PLOS ONE 15(5): e0233729.

Ruiz, H., Pavón, J. 1799. Flora peruviana, et chilensis. Vol. 2. Typis Gabrielis de Sancha, Madrid. 76 pp.

Smith, L.B. 1970. Boragináceas. En: Reitz, R. (Ed.) Flora llustrada Catarinense, pp. 3-85. Herbário 'Barbosa Rodrigues, Itajaí.

Troll, C., Monheim, F. 1985. Tagebücher der Reisen in Bolivien 1926, 1927. Steiner-Verl.-Wiesbaden-GmbH, Stuttgart. $390 \mathrm{pp}$.

Verdcourt, B. 1991. Boraginaceae. En: Polhill, R.M. (Ed.) Flora of Tropical East Africa, Vol. 152, pp. 1-124, Royal Botanic Gardens, Kew.

Zuloaga, F.O., Morrone, O., Belgrano, M.J. 2008. Catálogo de las plantas vasculares del Cono Sur (Argentina, Sur de Brasil, Chile, Paraguay y Uruguay). Missouri Botanical Garden Press, St. Louis. 3348 pp.

Received: 05.05.2020

Accepted: 11.08.2020 